\title{
Polymer grafting inside wood cellulose fibers by improved hydroxyl accessibility from fiber swelling
}

\section{Supporting information}

Peter Olsén*, Natalia Herrera and Lars A. Berglund

Wallenberg Wood Science Center, WWSC, Department of Fibre and Polymer Technology, KTH Royal Institute of Technology, Teknikringen 56-58, 10044 Stockholm, Sweden

\section{Contents}

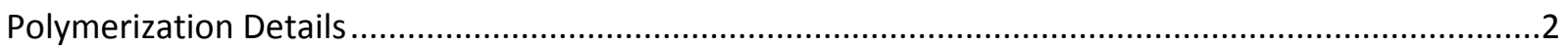

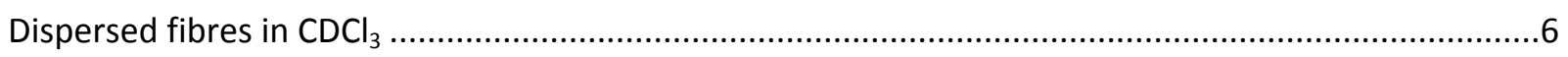

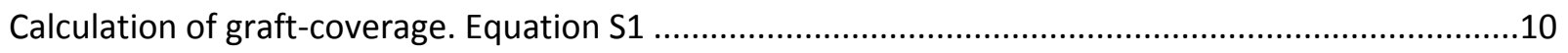

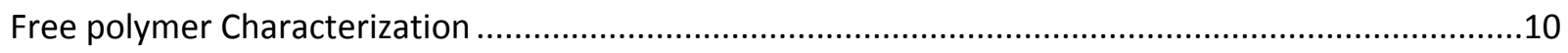




\section{Polymerization Details}
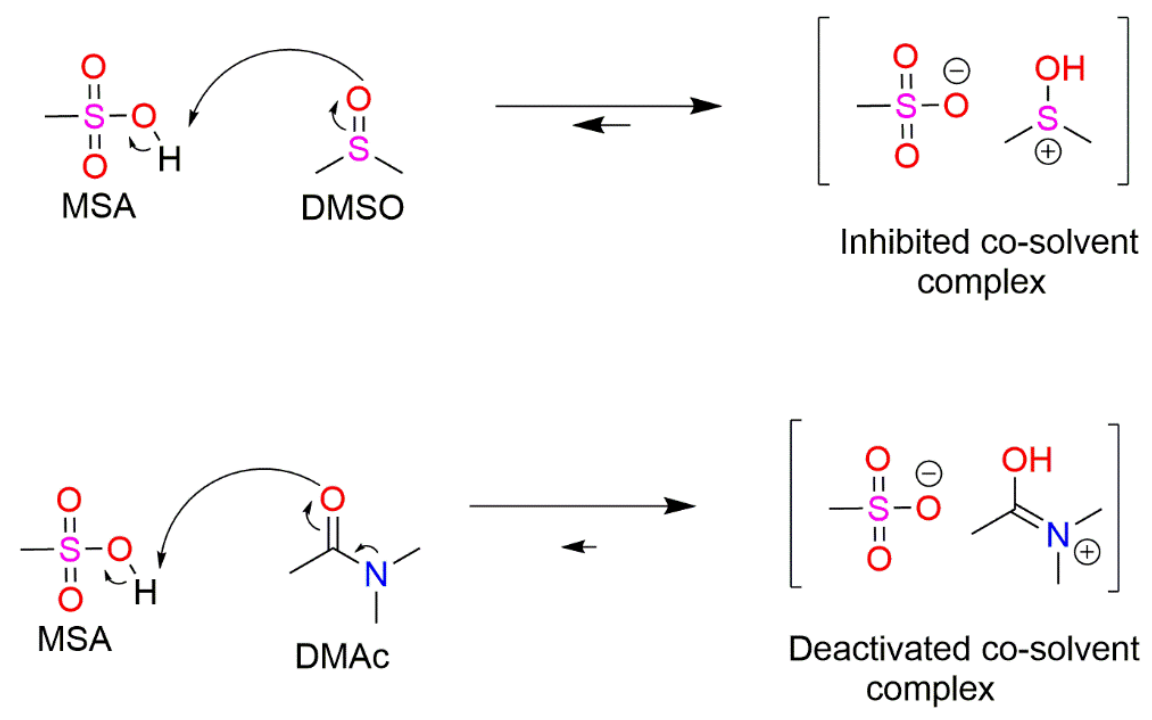

Scheme S1. Mechanistic description for co-solvent related catalyst deactivation. 

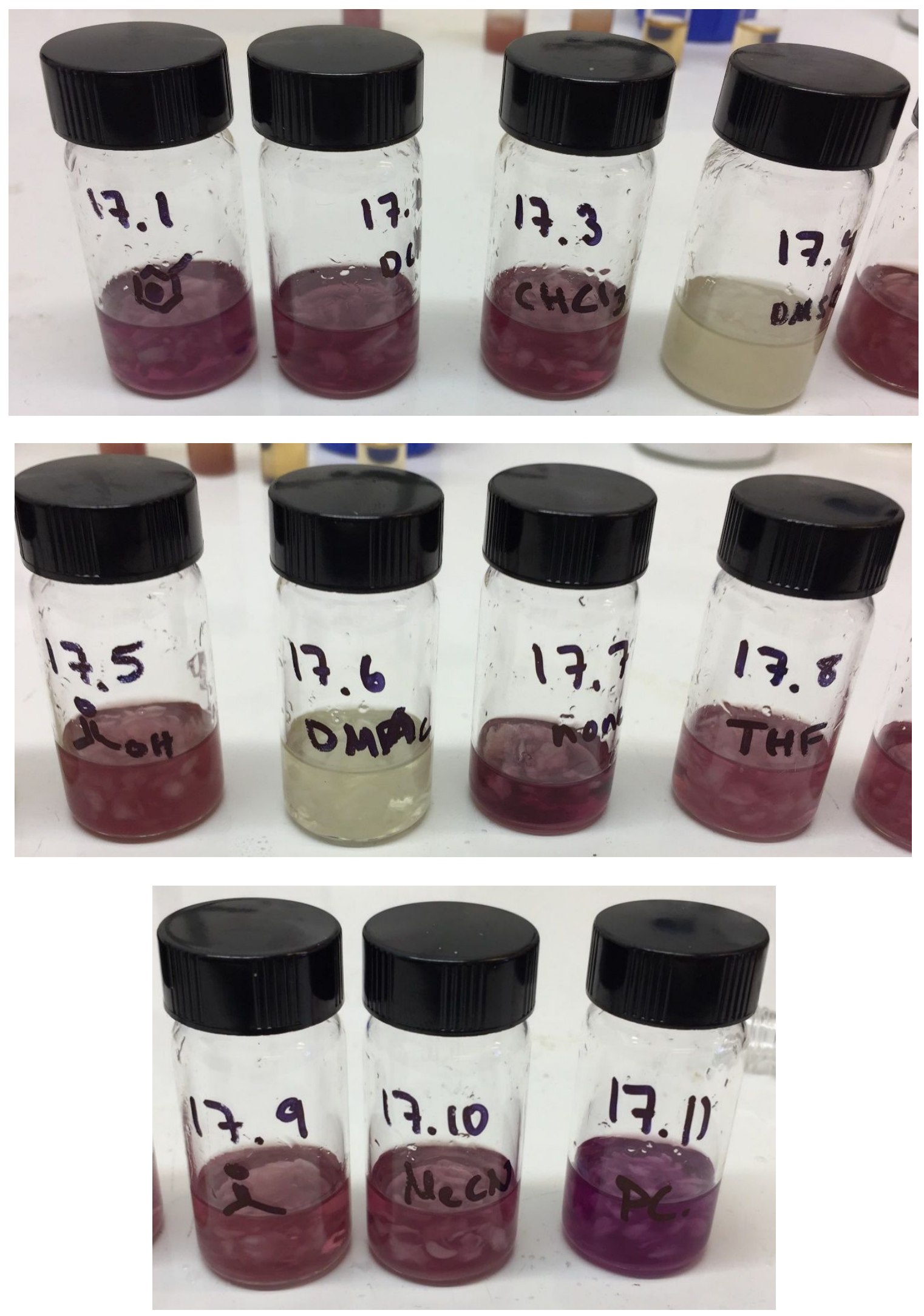
Figure S1. Activation of $\varepsilon \mathrm{CL}$ with MSA in different solvent systems with a CL:solvent weight ratio of 2:1.

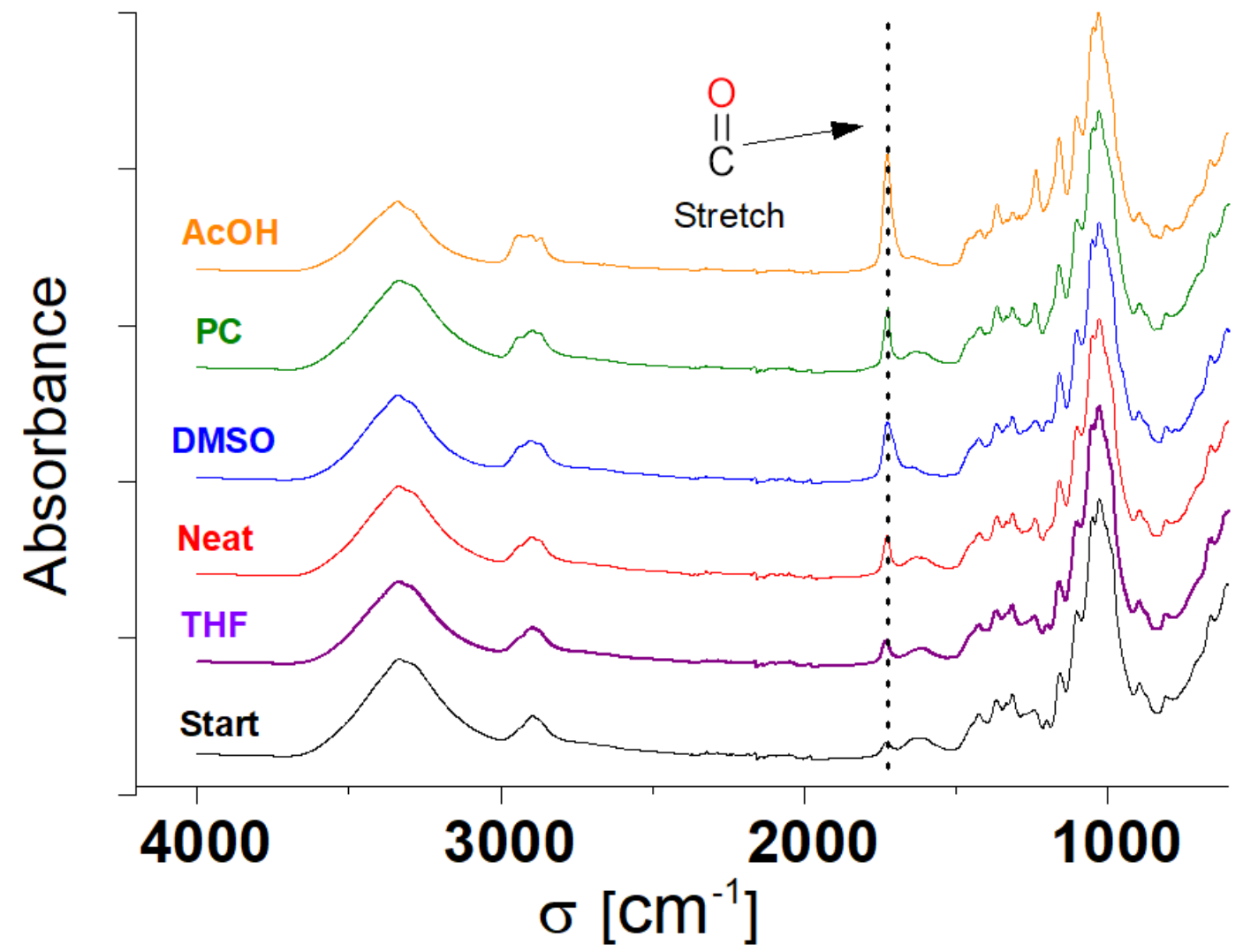

Figure S2. FTIR data over the grafted-HC fibres in different solvent systems 


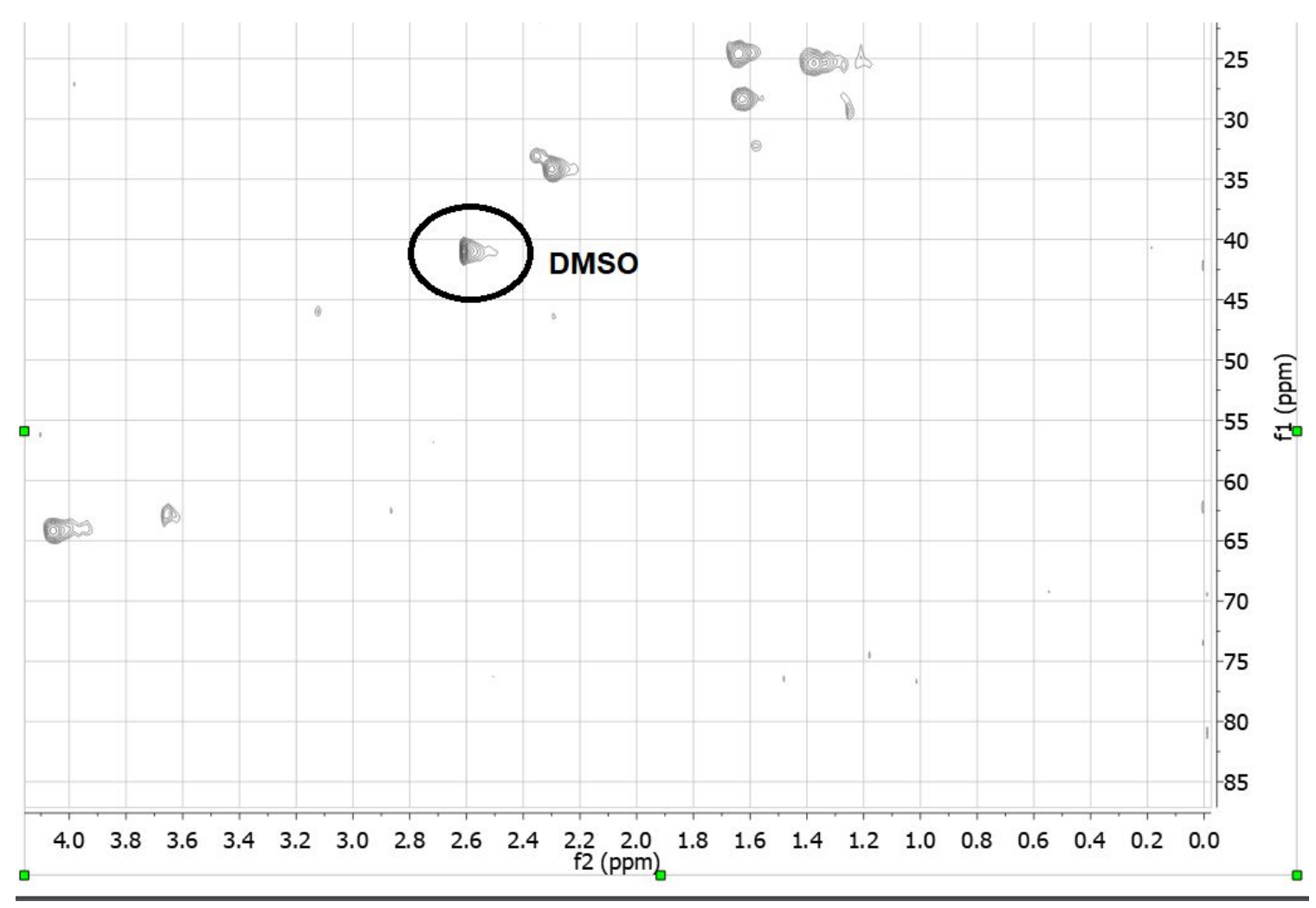

Figure S3. ${ }^{1} \mathrm{H}^{-13} \mathrm{C} \mathrm{HSQC}$ of $10 \mathrm{mg}$ hollocellulose grafted with $\mathrm{PCL}$ with $1 / 3(\mathrm{v} / \mathrm{v})$ of DMSO as a cosolvent, the analysis was performed in $1 \mathrm{ml} \mathrm{CDCl}$. Showing that some DMSO still is present around the fibers.

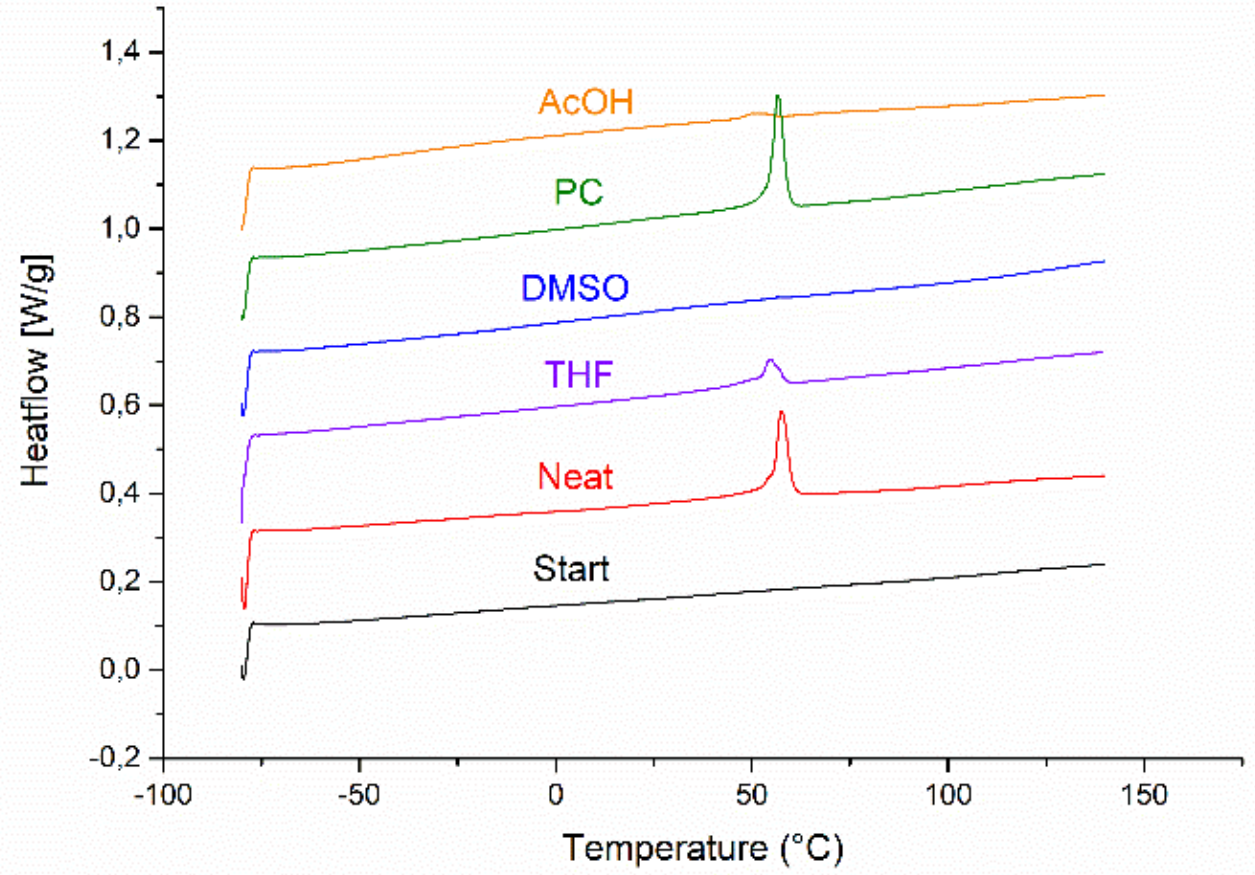

Figure S4. DSC data over the grafted-HC fibres in different solvent systems 


\section{Dispersed fibres in $\mathrm{CDCl}_{3}$}

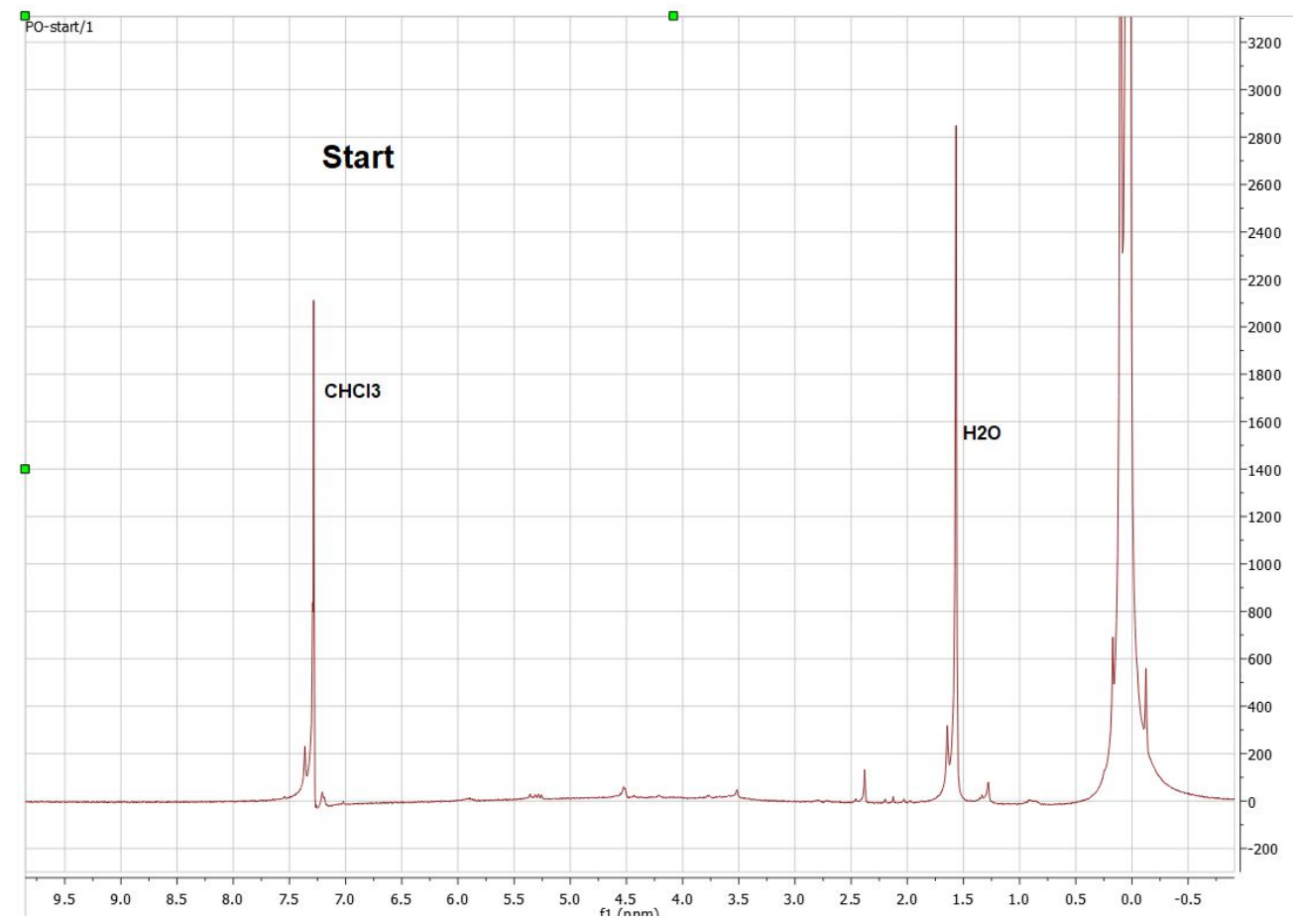

Figure S5. ${ }^{1} \mathrm{H}$ NMR of $10 \mathrm{mg}$ of Hollocellulose in $1 \mathrm{ml}$ of $\mathrm{CDCl}_{3}$

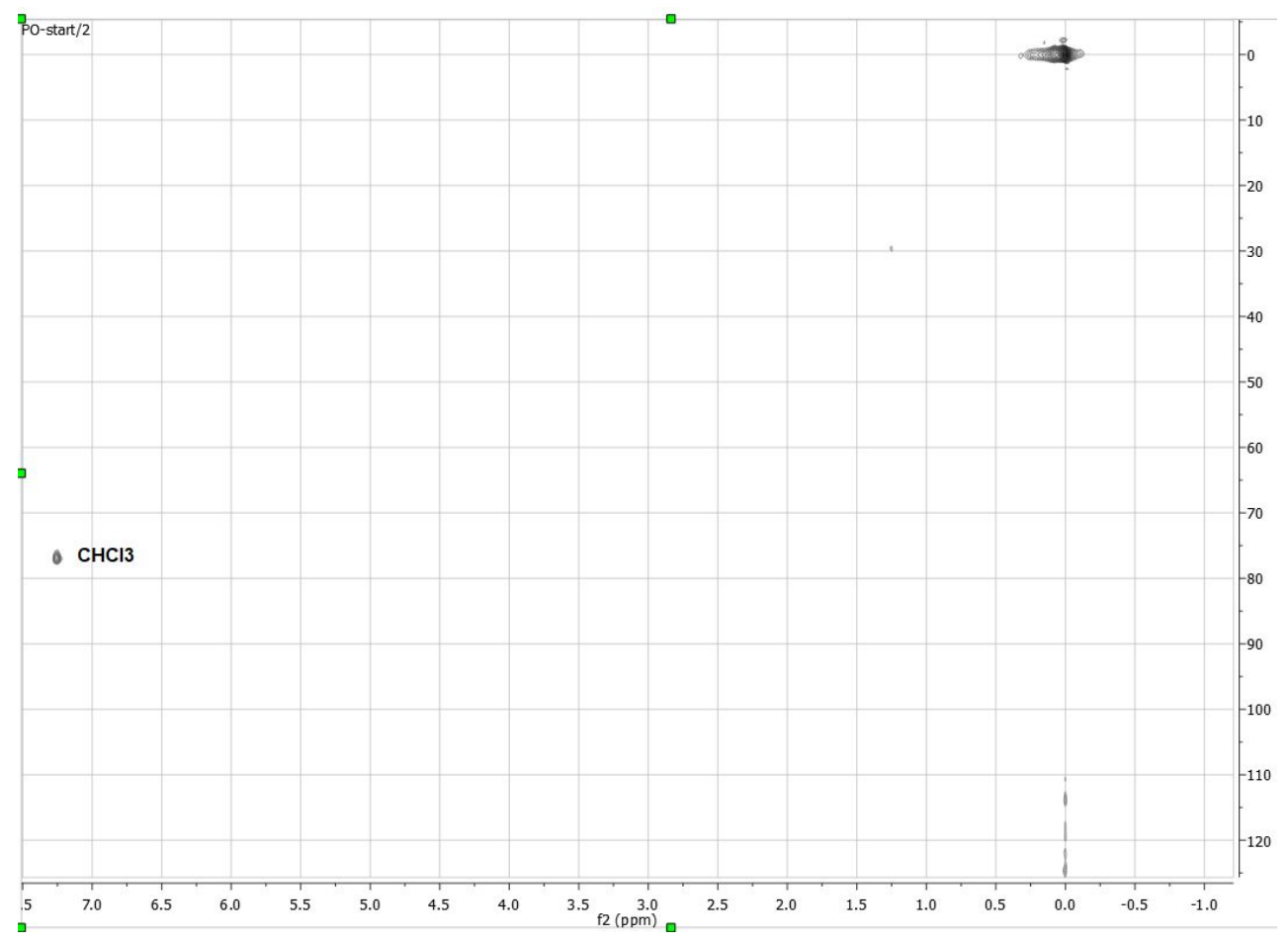

Figure S6. ${ }^{1} \mathrm{H}^{-13} \mathrm{C} \mathrm{HSQC}$ of $10 \mathrm{mg}$ of Hollocellulose in $1 \mathrm{ml}$ of $\mathrm{CDCl}_{3}$ 


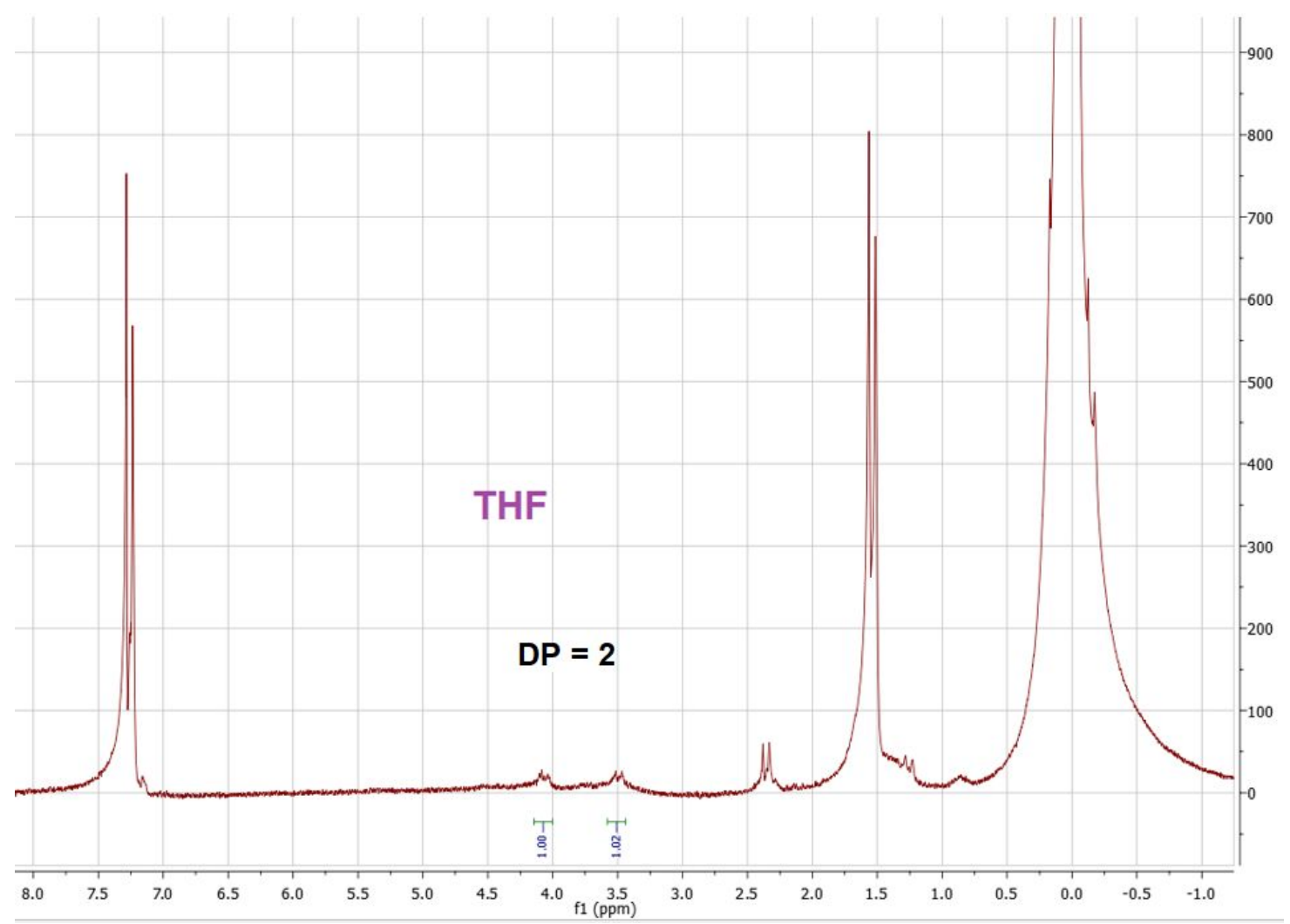

Figure S7. ${ }^{1} \mathrm{H}$ NMR of $10 \mathrm{mg}$ hollocellulose grafted with $\mathrm{PCL}$ with $1 / 3(\mathrm{v} / \mathrm{v})$ of THF as a solvent, the analysis was performed in $1 \mathrm{ml} \mathrm{CDCl}$.

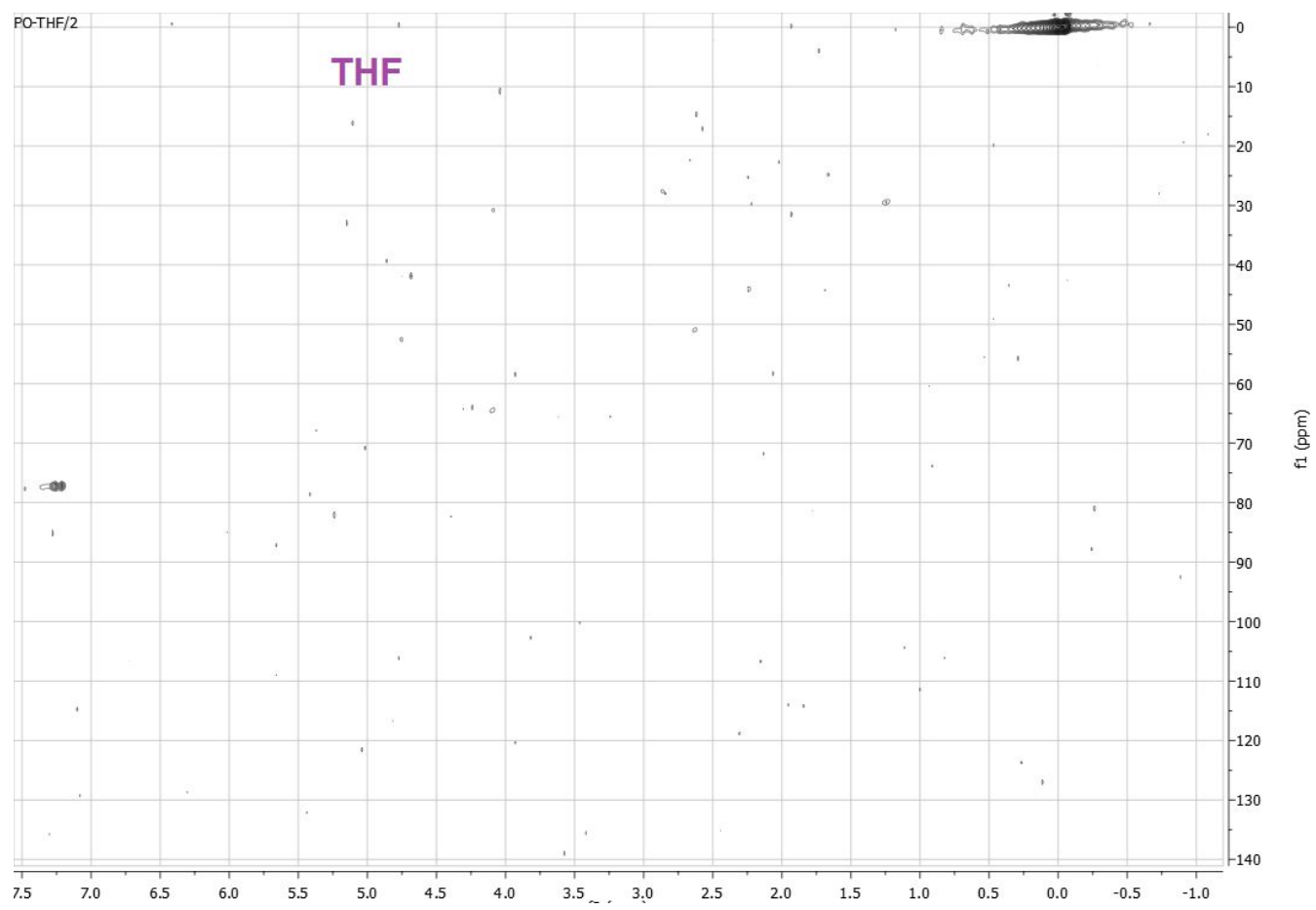

Figure S8. ${ }^{1} \mathrm{H}-{ }^{13} \mathrm{C} \mathrm{HSQC}$ of $10 \mathrm{mg}$ hollocellulose grafted with $\mathrm{PCL}$ with $1 / 3(\mathrm{v} / \mathrm{v})$ of THF as a solvent, the analysis was performed in $1 \mathrm{ml} \mathrm{CDCl}$. 


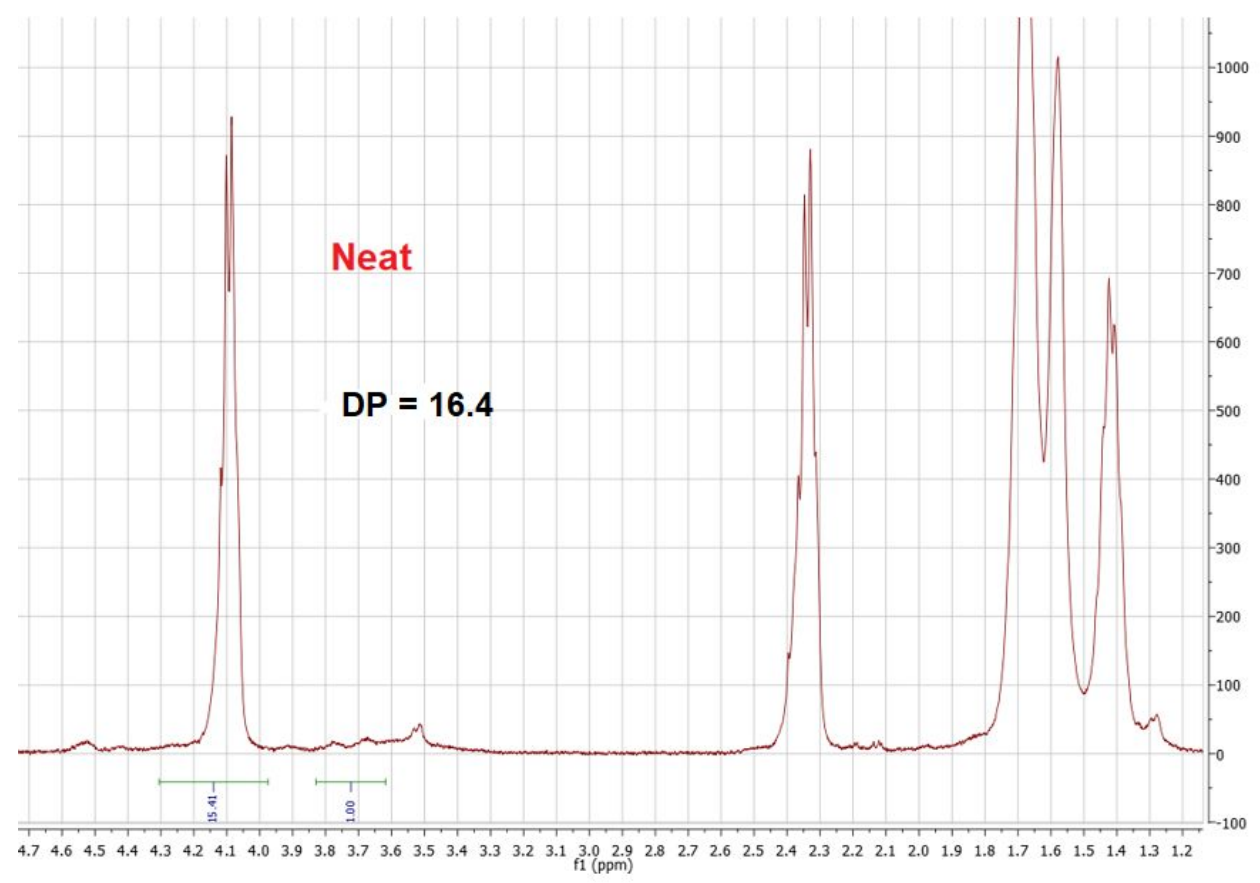

Figure S9. ${ }^{1 \mathrm{H}} \mathrm{NMR}$ of $10 \mathrm{mg}$ hollocellulose grafted with $\mathrm{PCL}$ under neat conditions, the analysis was performed in $1 \mathrm{ml} \mathrm{CDCl}_{3}$.

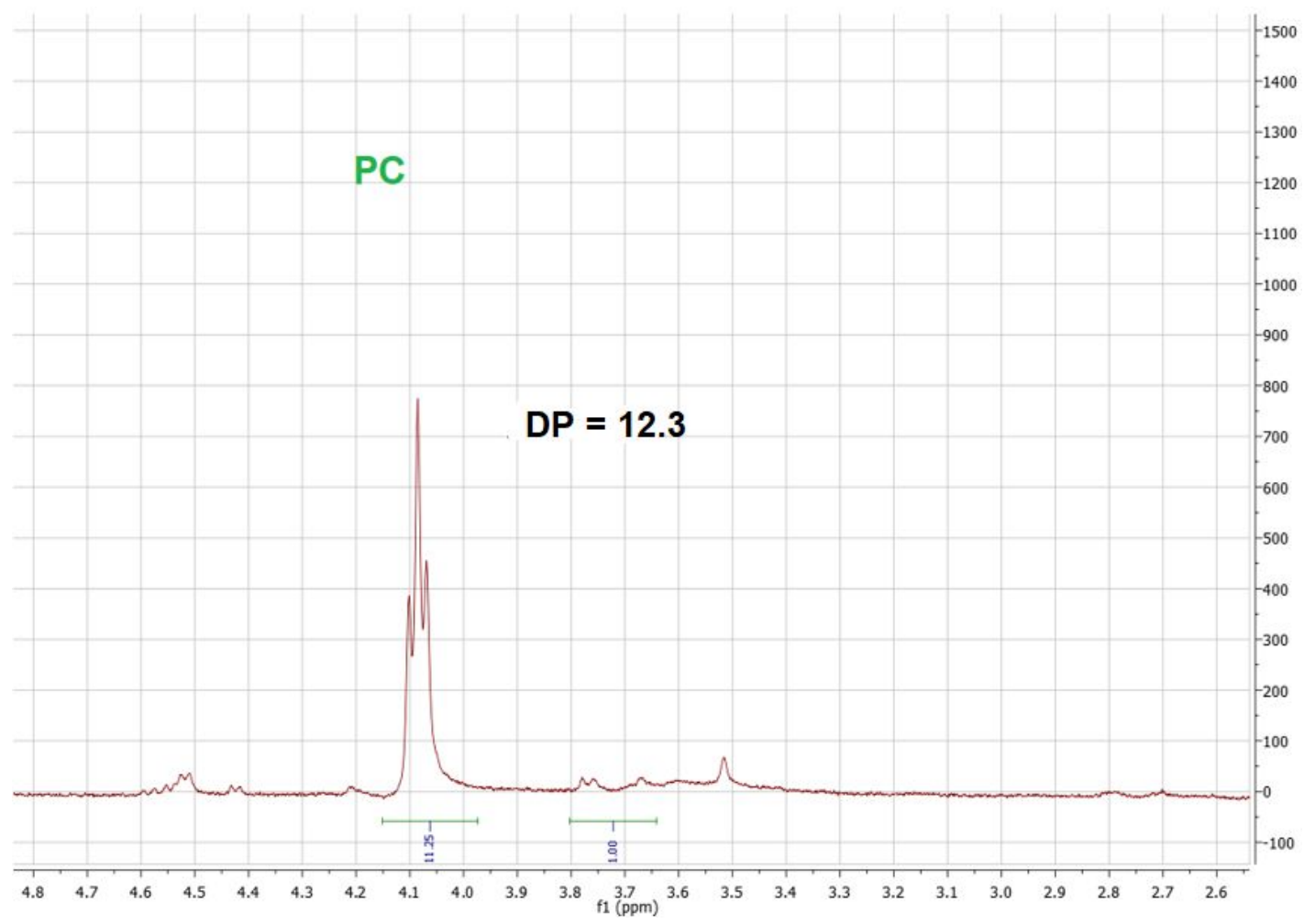

Figure S10. ${ }^{1} \mathrm{H}$ NMR of $10 \mathrm{mg}$ hollocellulose grafted with PCL with $1 / 3(\mathrm{v} / \mathrm{v})$ of $\mathrm{PC}$ as a solvent, the analysis was performed in $1 \mathrm{ml} \mathrm{CDCl}$. 


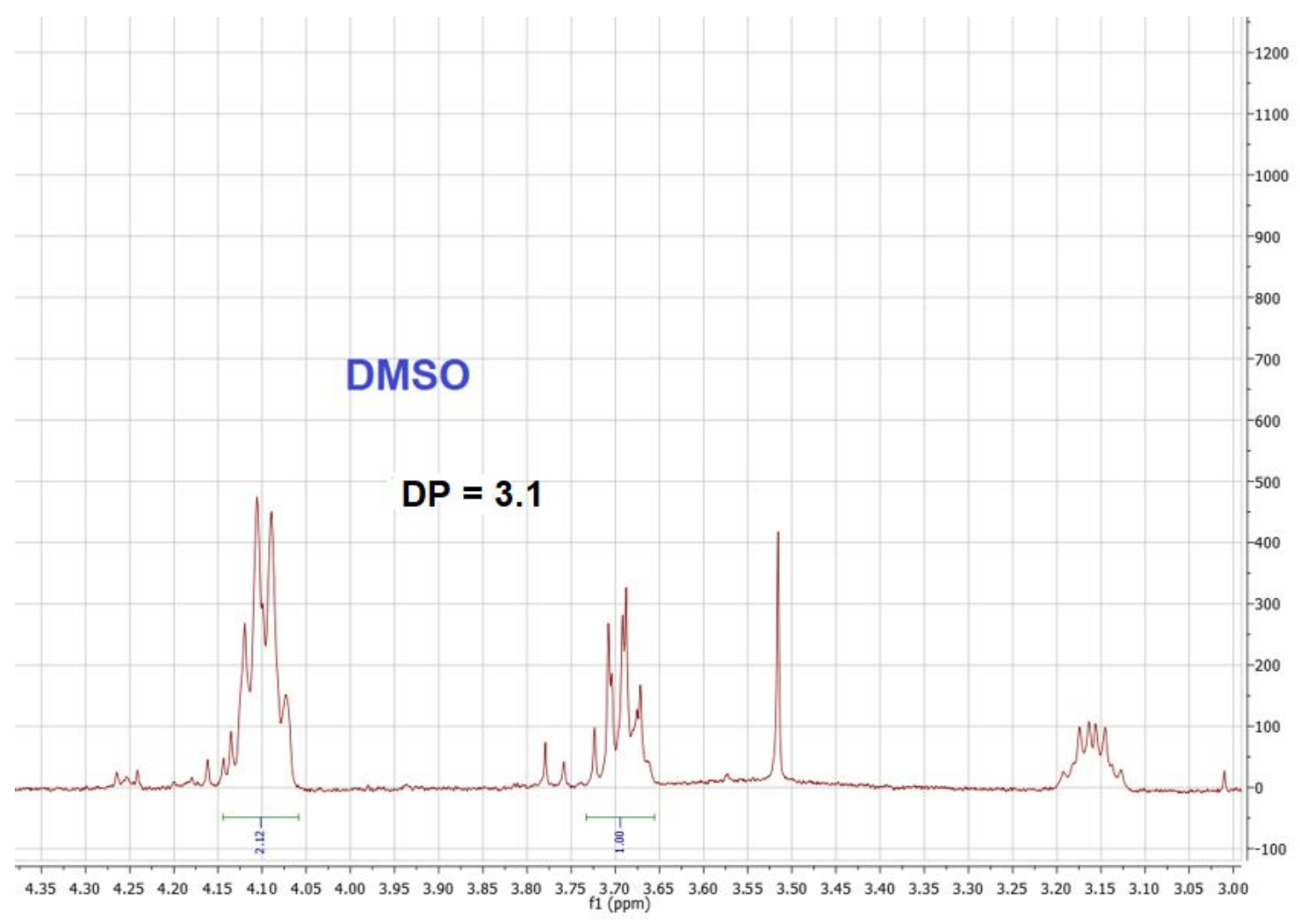

Figure S11. ${ }^{1} \mathrm{H}$ NMR of $10 \mathrm{mg}$ hollocellulose grafted with PCL with $1 / 3(\mathrm{v} / \mathrm{v})$ of DMSO as a solvent, the analysis was performed in $1 \mathrm{ml} \mathrm{CDCl}_{3}$.

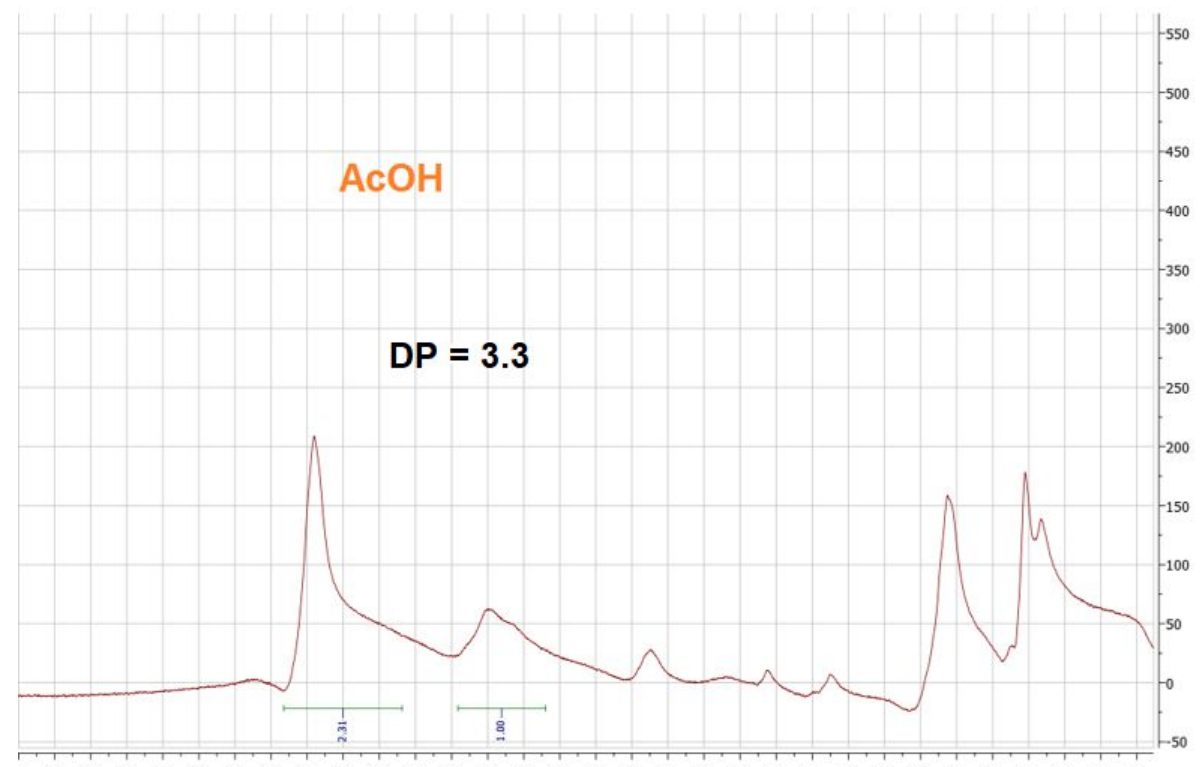

$\begin{array}{lllllllllllllllllllllllllllllllllllllll}9 & 4.8 & 4.7 & 4.6 & 4.5 & 4.4 & 4.3 & 4.2 & 4.1 & 4.0 & 3.9 & 3.8 & 3.7 & 3.6 & 3.5 & 3.4 & 3.3 & 3.2 & 3.1 & 3.0 & 2.9 & 2.8 & 2.7 & 2.6 & 2.5 & 2.4 & 2.3 & 2.2 & 2.1 & 2.0 & 1.9 & 1.8\end{array}$

Figure S12. ${ }^{1} \mathrm{H}$ NMR of $10 \mathrm{mg}$ hollocellulose grafted with $\mathrm{PCL}$ with $1 / 3(\mathrm{v} / \mathrm{v})$ of $\mathrm{AcOH}$ as a solvent, the analysis was performed in $1 \mathrm{ml} \mathrm{CDCl}$. 
Calculation of graft-coverage. Equation S1

(Weight Change in gram) $/\left(\left(D P * M_{C L}{ }^{*}{ }^{*}\right.\right.$ Surface area)

\section{Free polymer Characterization}

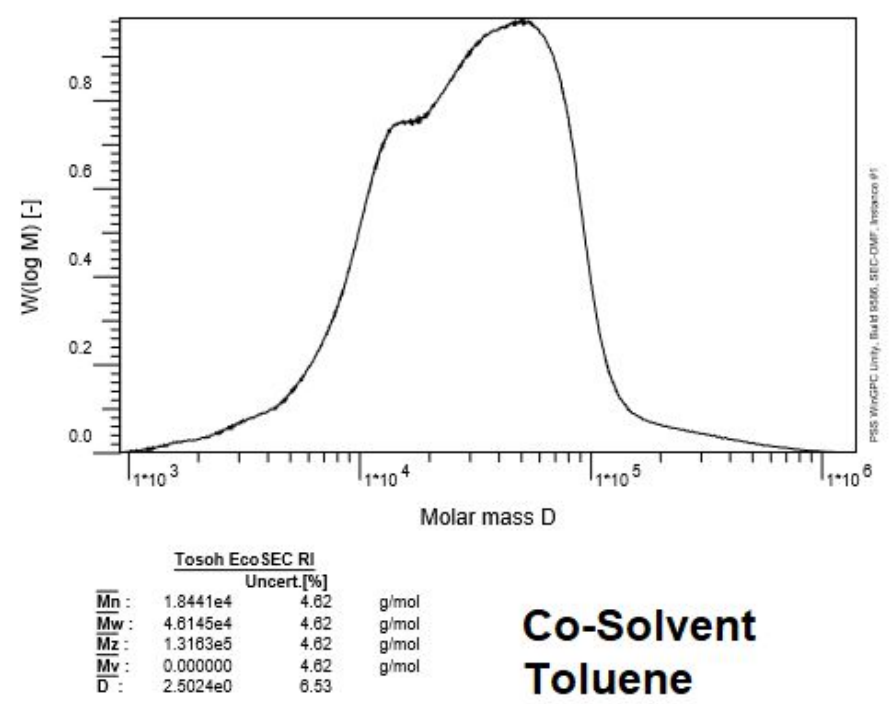

Figure S13. GPC traces for the free chains after SI-ROP in toluene as a solvent 


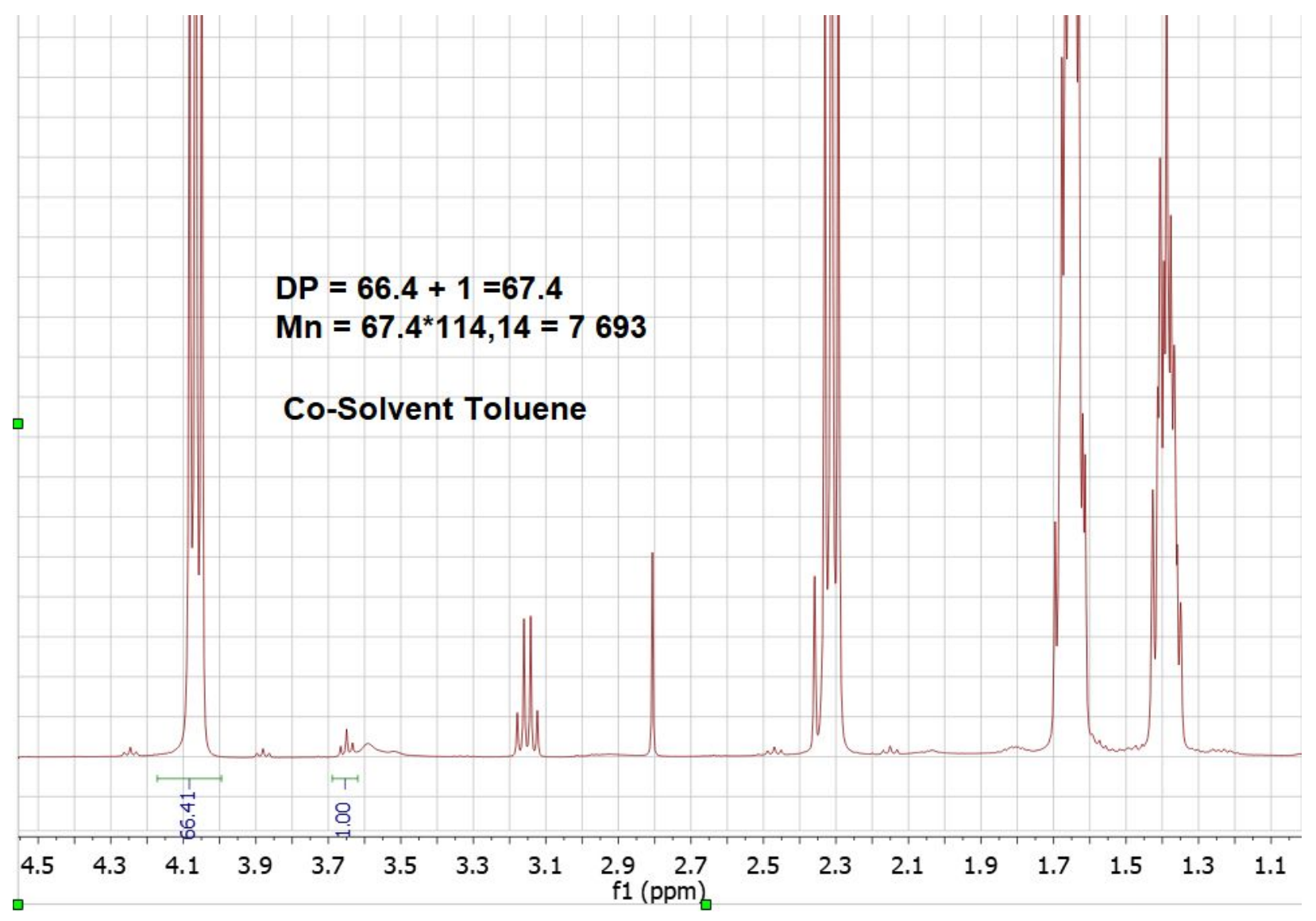

Figure S14. ${ }^{1} \mathrm{H}$ NMR for the free chains after SI-ROP in toluene as a solvent 

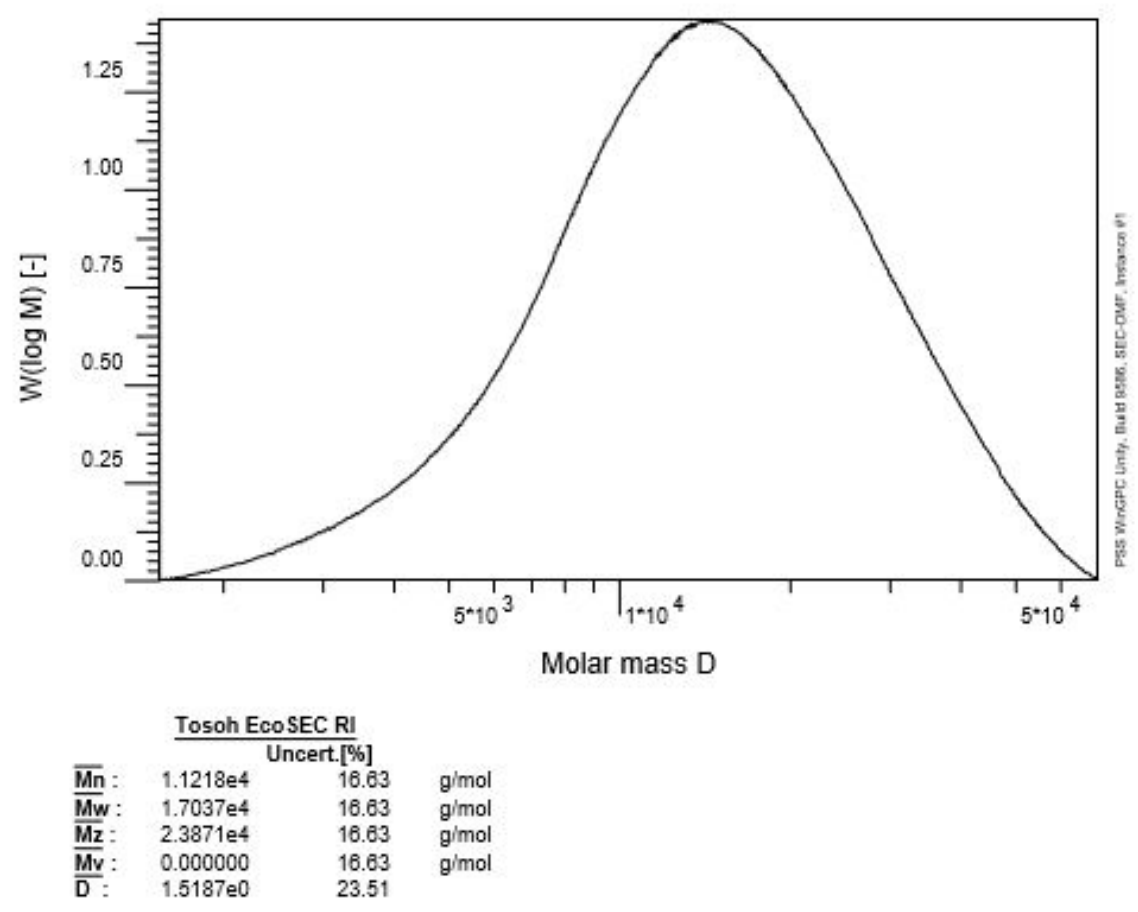

Figure S15. GPC traces for the free chains after SI-ROP in Chloroform as a solvent

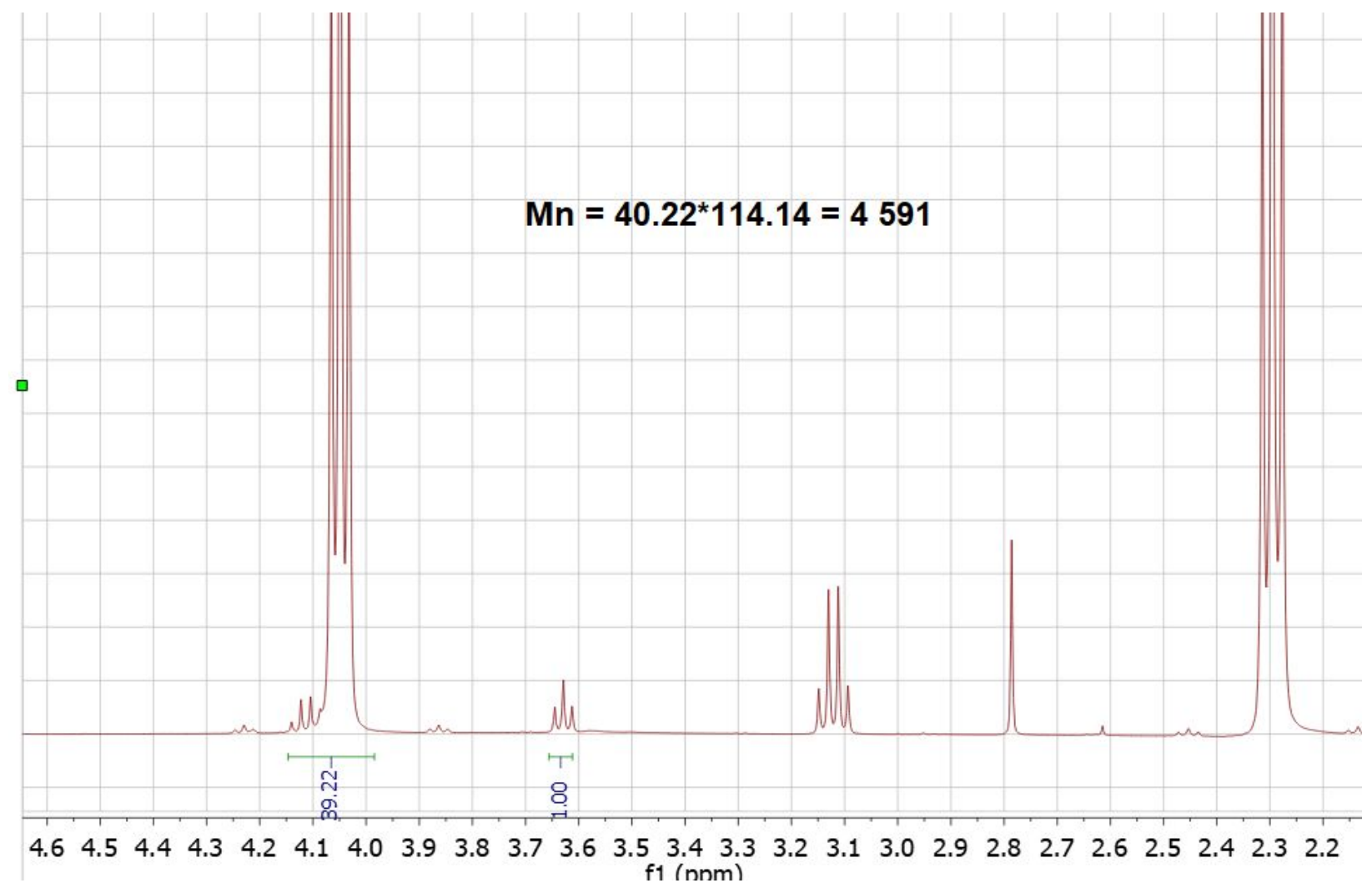

Figure S16. ${ }^{1} \mathrm{H}$ NMR for the free chains after SI-ROP in chloroform as a solvent 


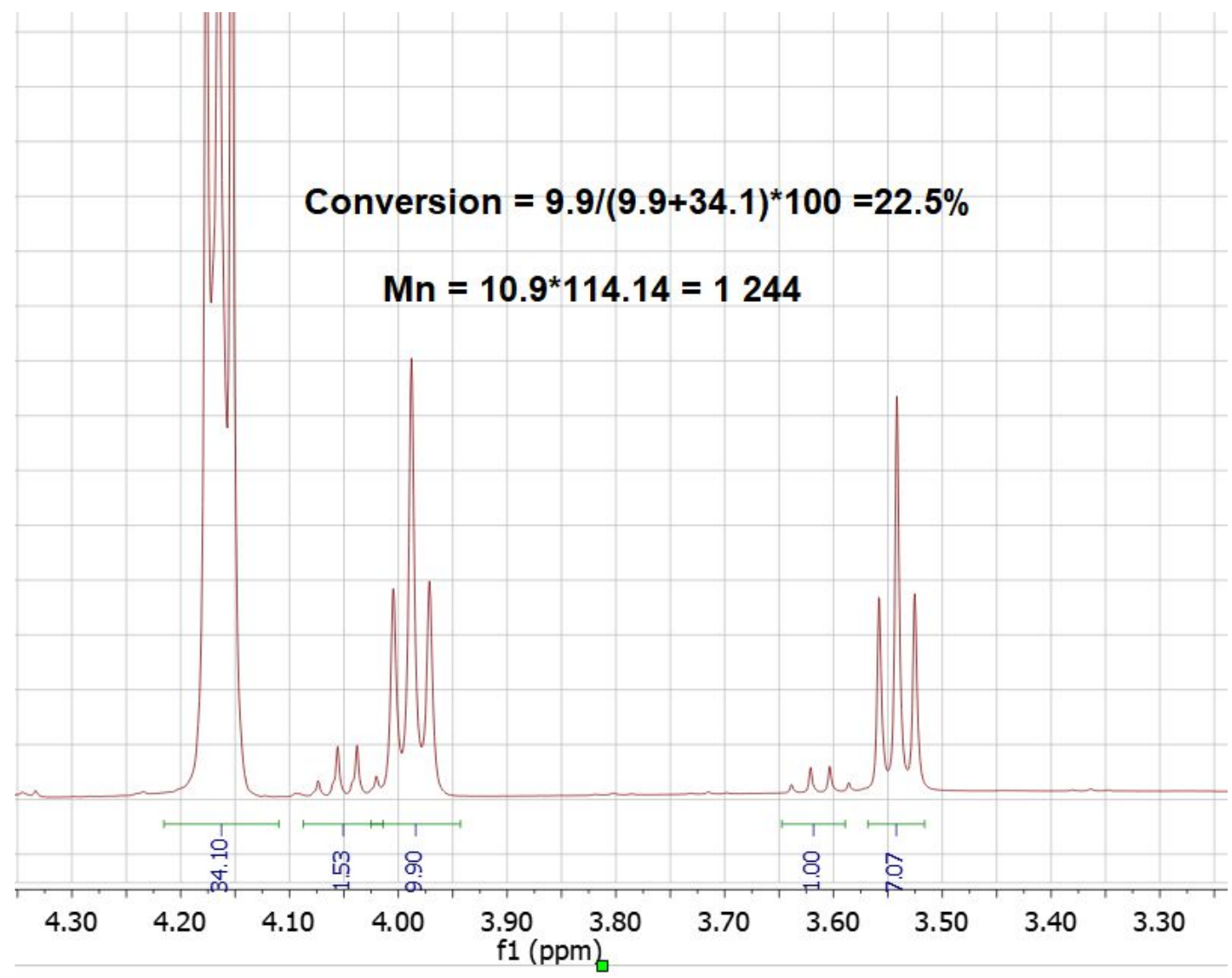

Figure S17. ${ }^{1} \mathrm{H}$ NMR for the free chains after SI-ROP in DMSO as a solvent

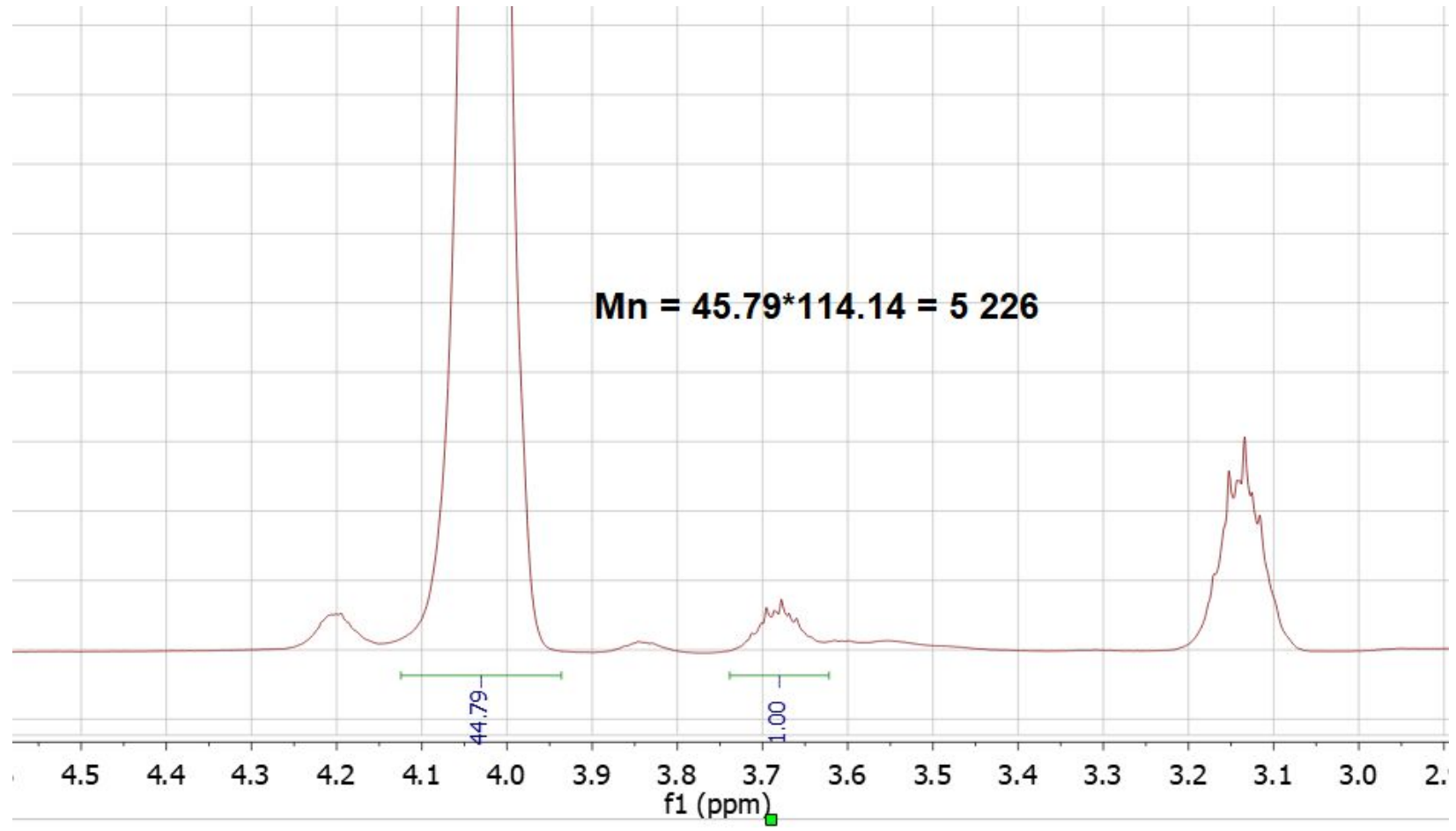

Figure S18. ${ }^{1} \mathrm{H}$ NMR for the free chains after SI-ROP in $\mathrm{AcOH}$ as a solvent 


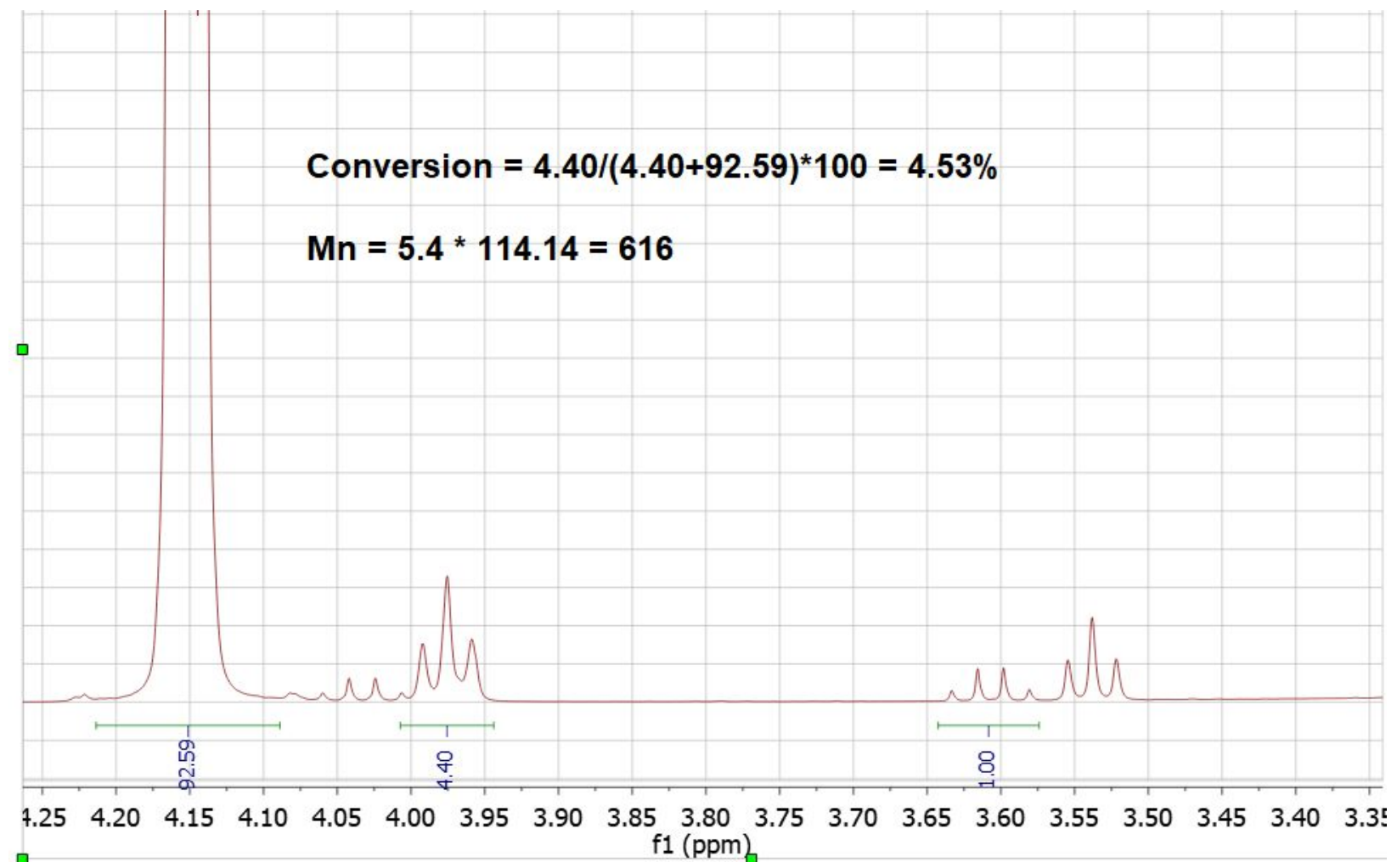

Figure S19. ${ }^{1} \mathrm{H}$ NMR for the free chains after SI-ROP in DMAc as a solvent

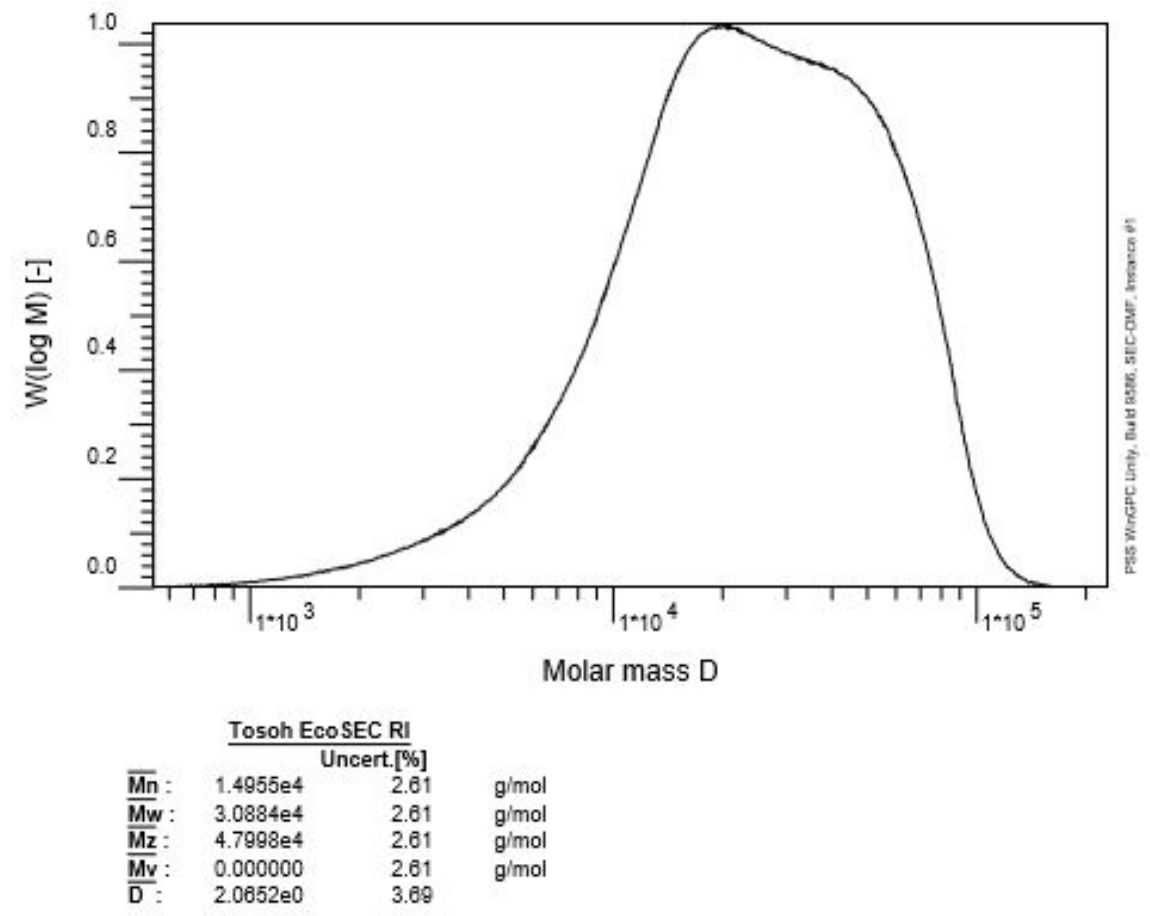

Figure S20. GPC traces for the free chains after SI-ROP under neat conditions 


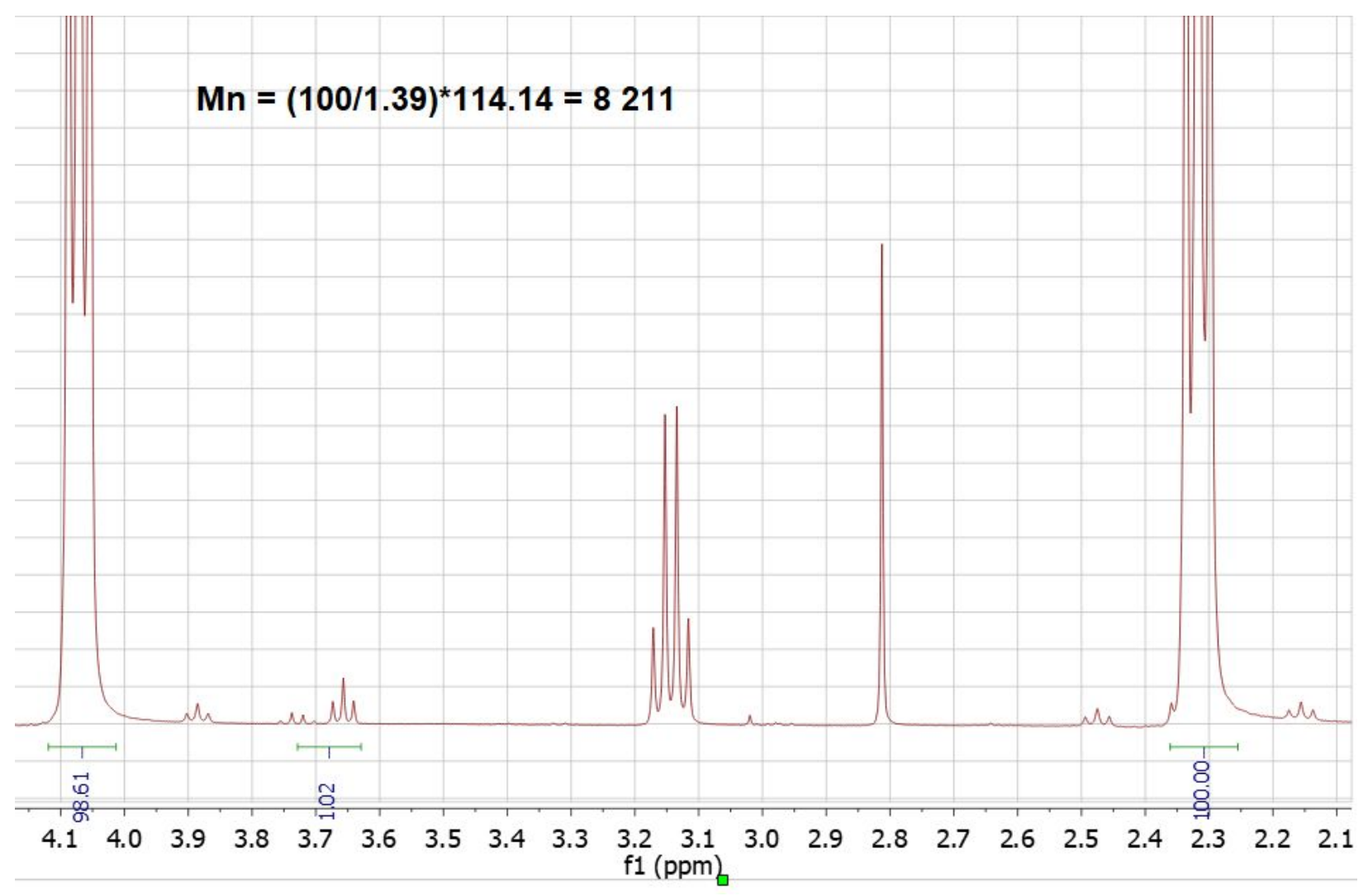

Figure S21. ${ }^{1} \mathrm{H}$ NMR for the free chains after SI-ROP under neat conditions

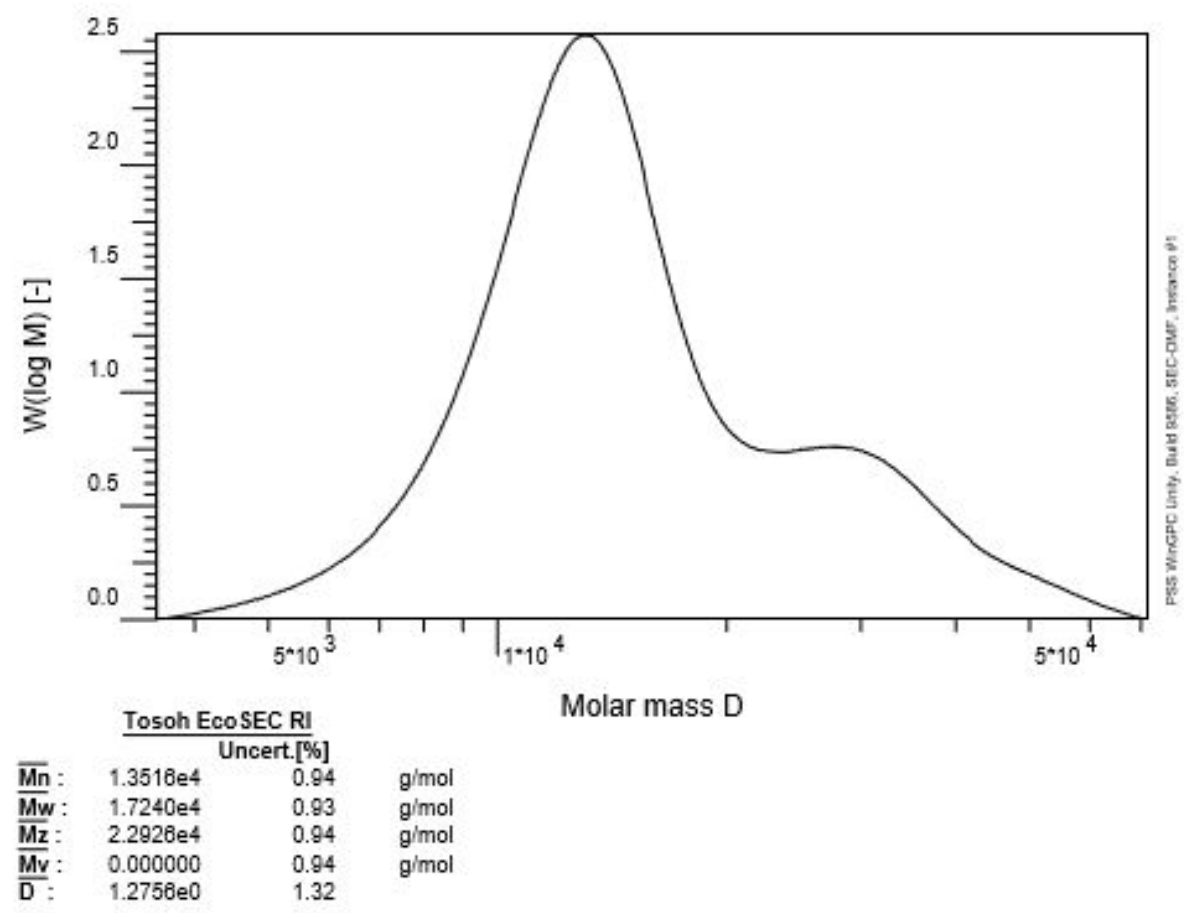

Figure S22. GPC traces for the free chains after SI-ROP in THF as a solvent 


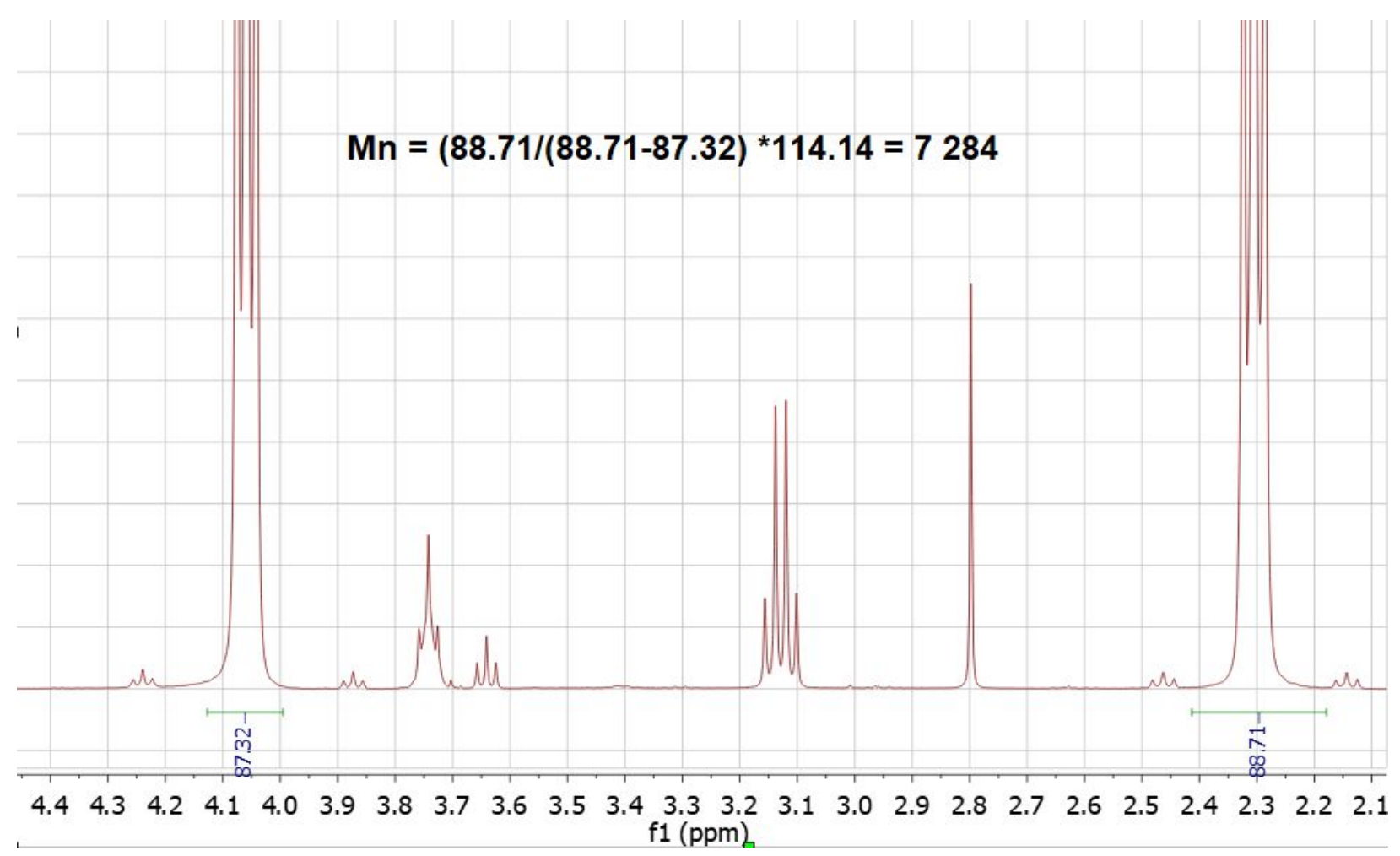

Figure S23. ${ }^{1} \mathrm{H}$ NMR for the free chains after SI-ROP in THF as a solvent

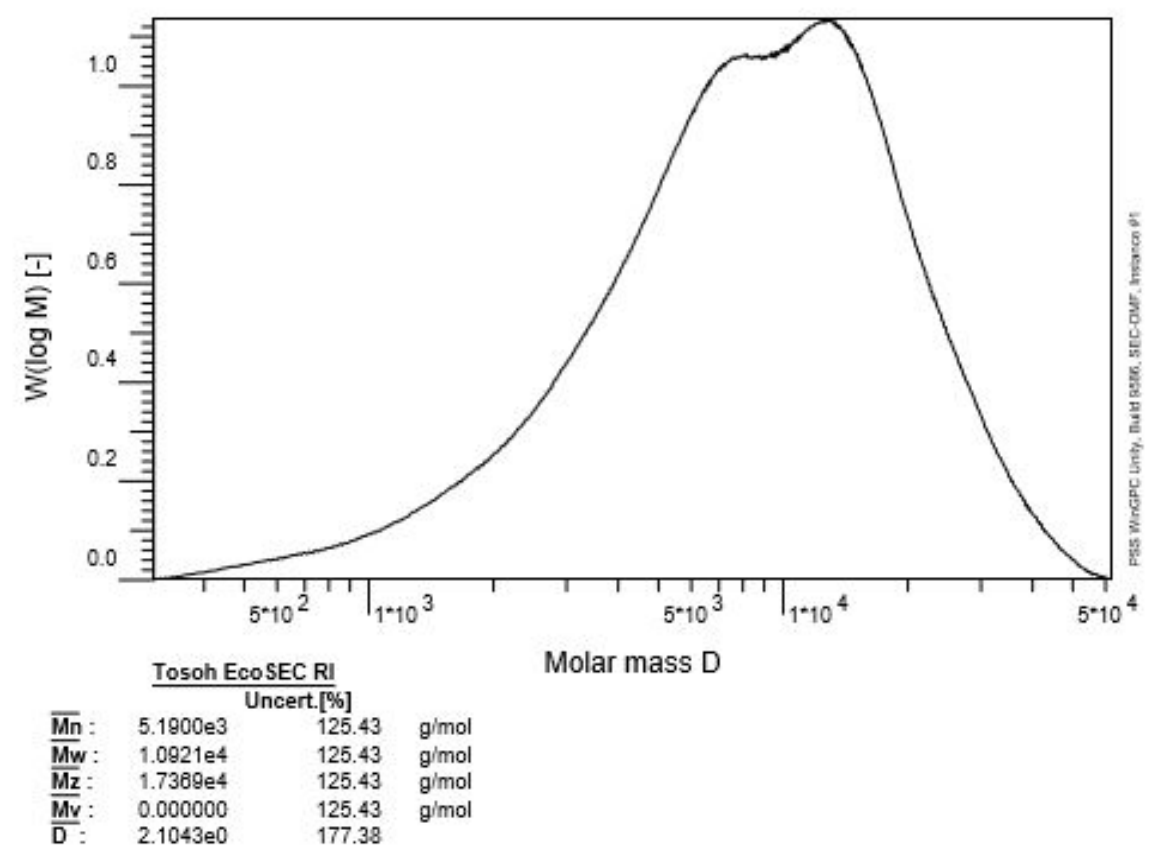

Figure S24. GPC traces for the free chains after SI-ROP in Acetone as a solvent 


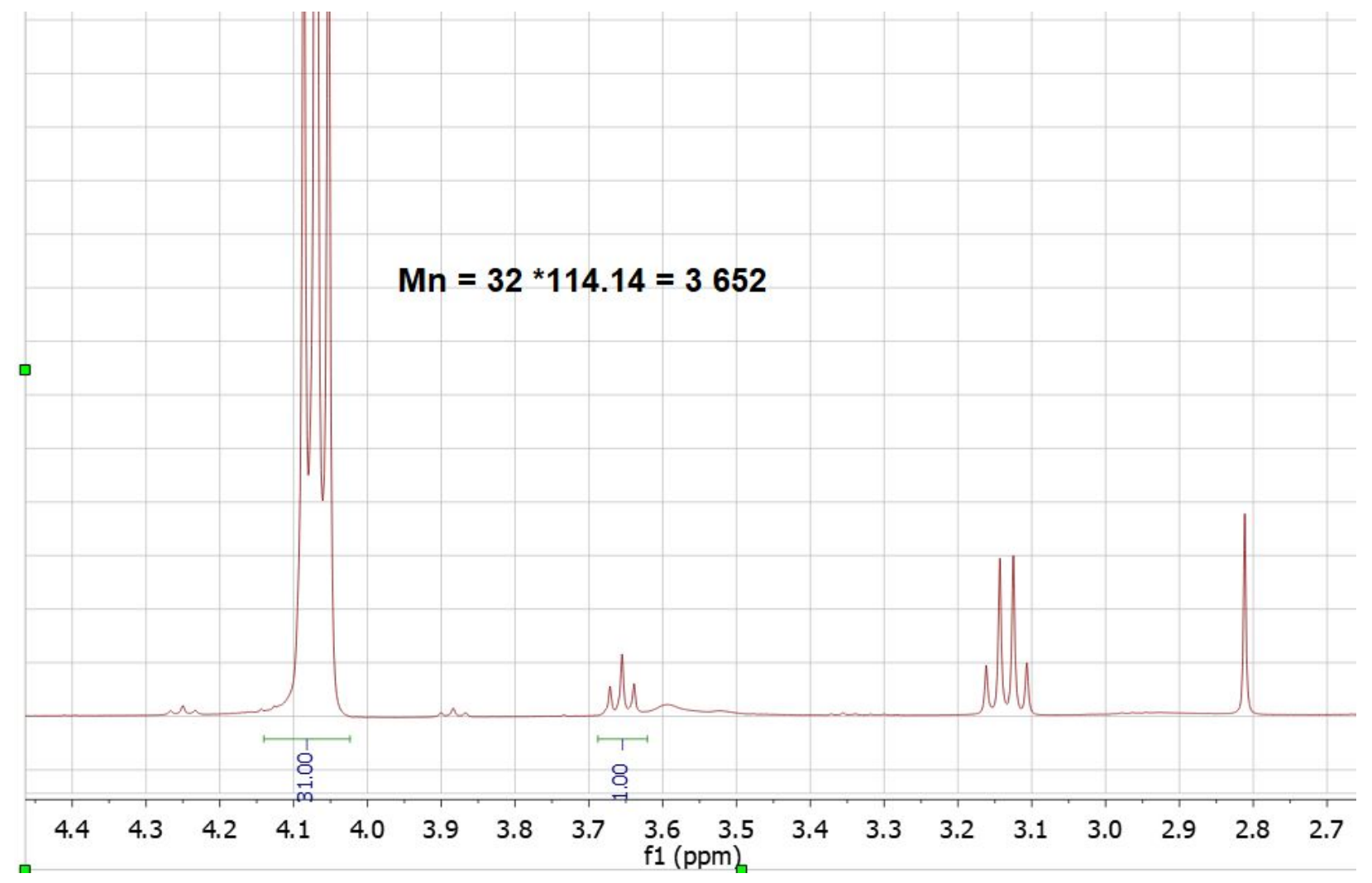

Figure S25. ${ }^{1} \mathrm{H}$ NMR for the free chains after SI-ROP in Acetone as a solvent

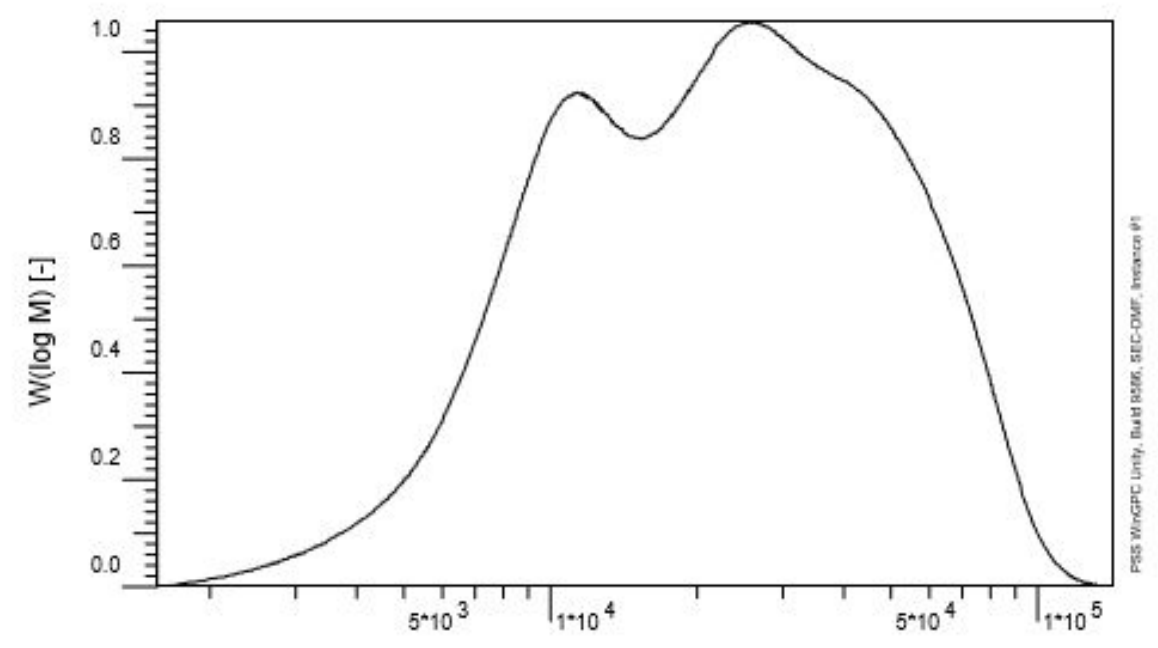

\begin{tabular}{lrrl} 
& \multicolumn{3}{c}{ Tosoh EcoSEC RI } \\
$:$ & $1.5730 \mathrm{e} 4$ & Uncert.[\%] & \\
$\overline{\mathrm{Mn}}:$ & $2.8496 \mathrm{e} 4$ & 1.93 & $\mathrm{~g} / \mathrm{mol}$ \\
$\overline{\mathrm{Mz}}:$ & $4.3832 \mathrm{e} 4$ & 1.93 & $\mathrm{~g} / \mathrm{mol}$ \\
$\overline{\mathrm{Mv}}:$ & 0.000000 & 1.93 & $\mathrm{~g} / \mathrm{mol}$ \\
$\overline{\mathrm{D}}:$ & $1.8116 \mathrm{e} 0$ & 2.72 & $\mathrm{~g} / \mathrm{mol}$ \\
& &
\end{tabular}

Figure S26. GPC traces for the free chains after SI-ROP in MeCN as a solvent 


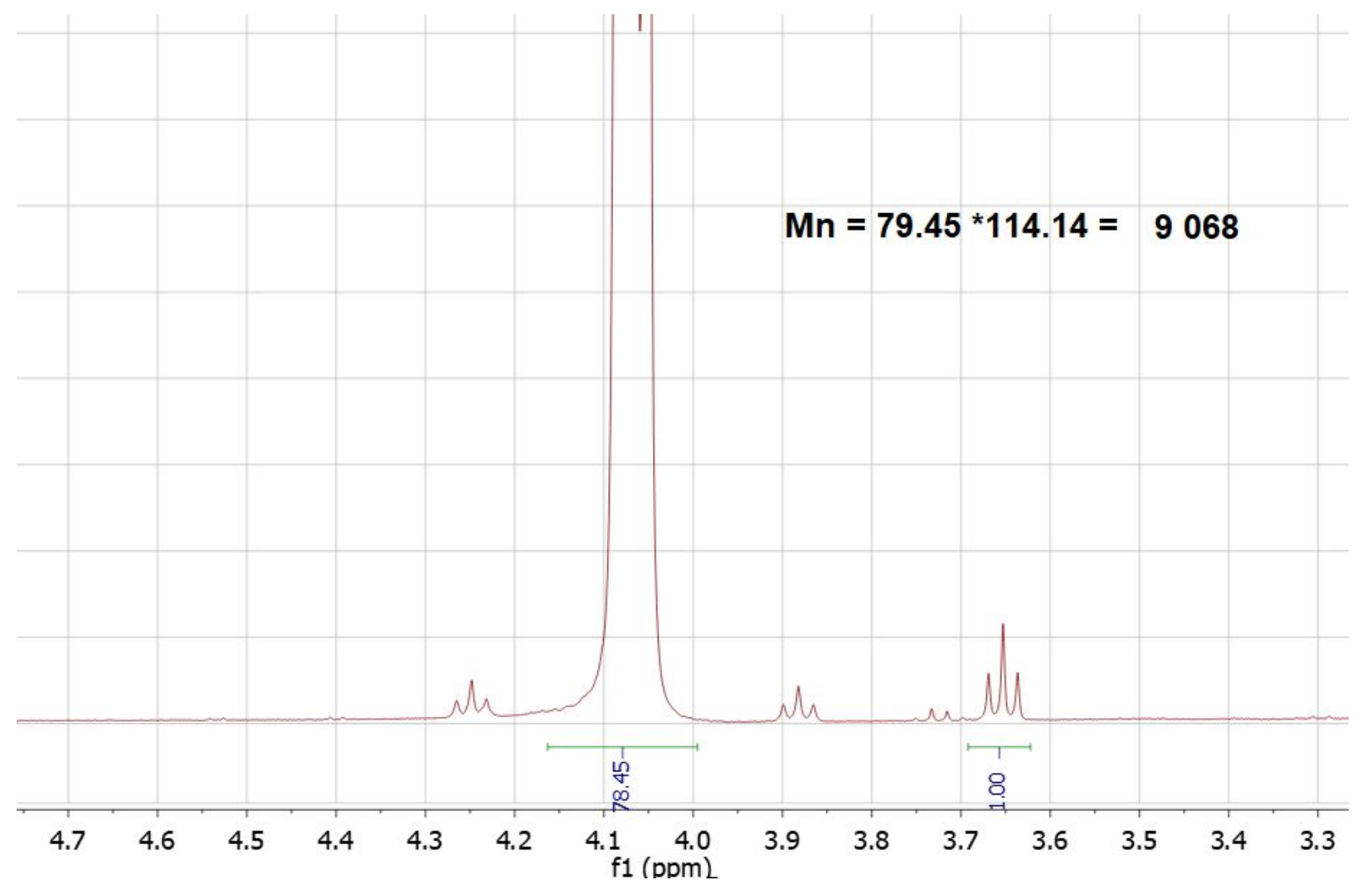

Figure S27. ${ }^{1} \mathrm{H}$ NMR for the free chains after SI-ROP in MeCN as a solvent

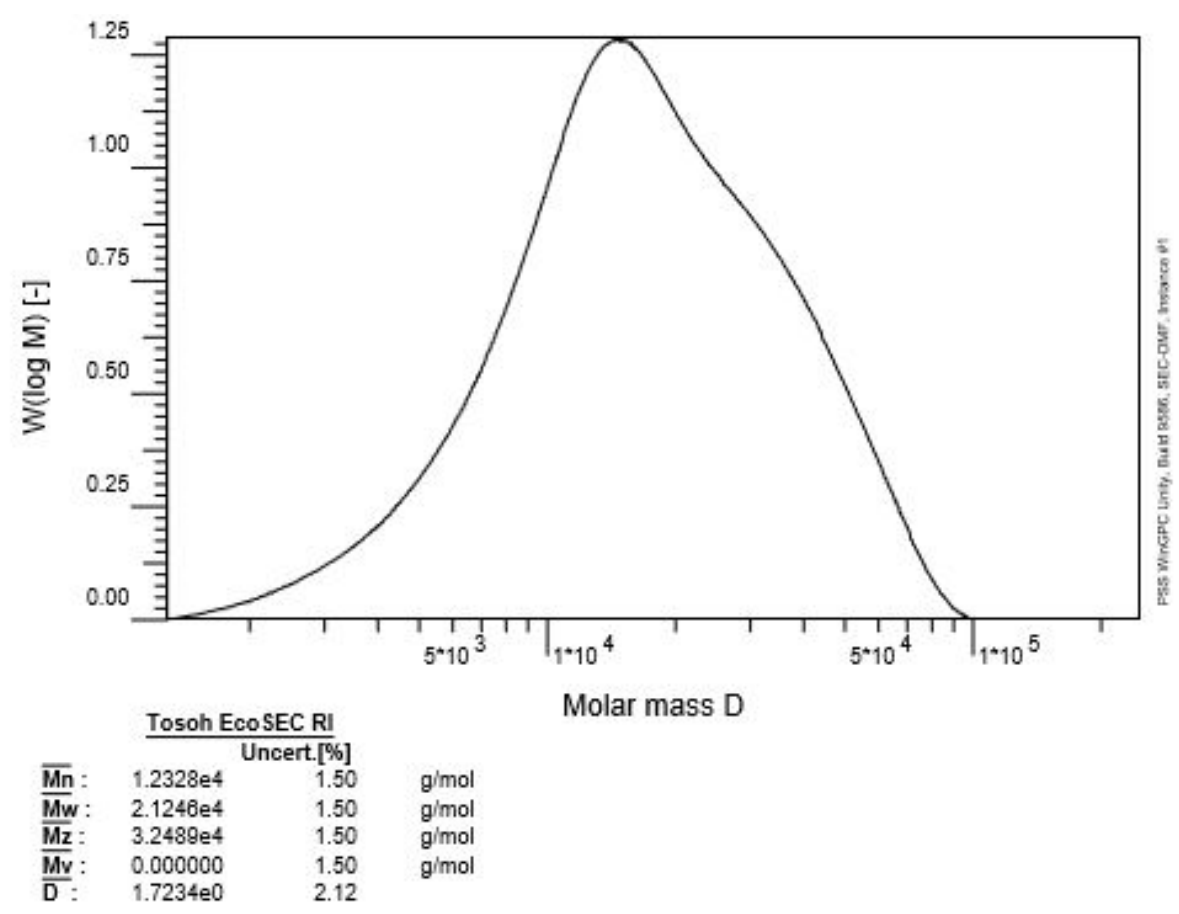

Figure S28. GPC traces for the free chains after SI-ROP in PC as a solvent 


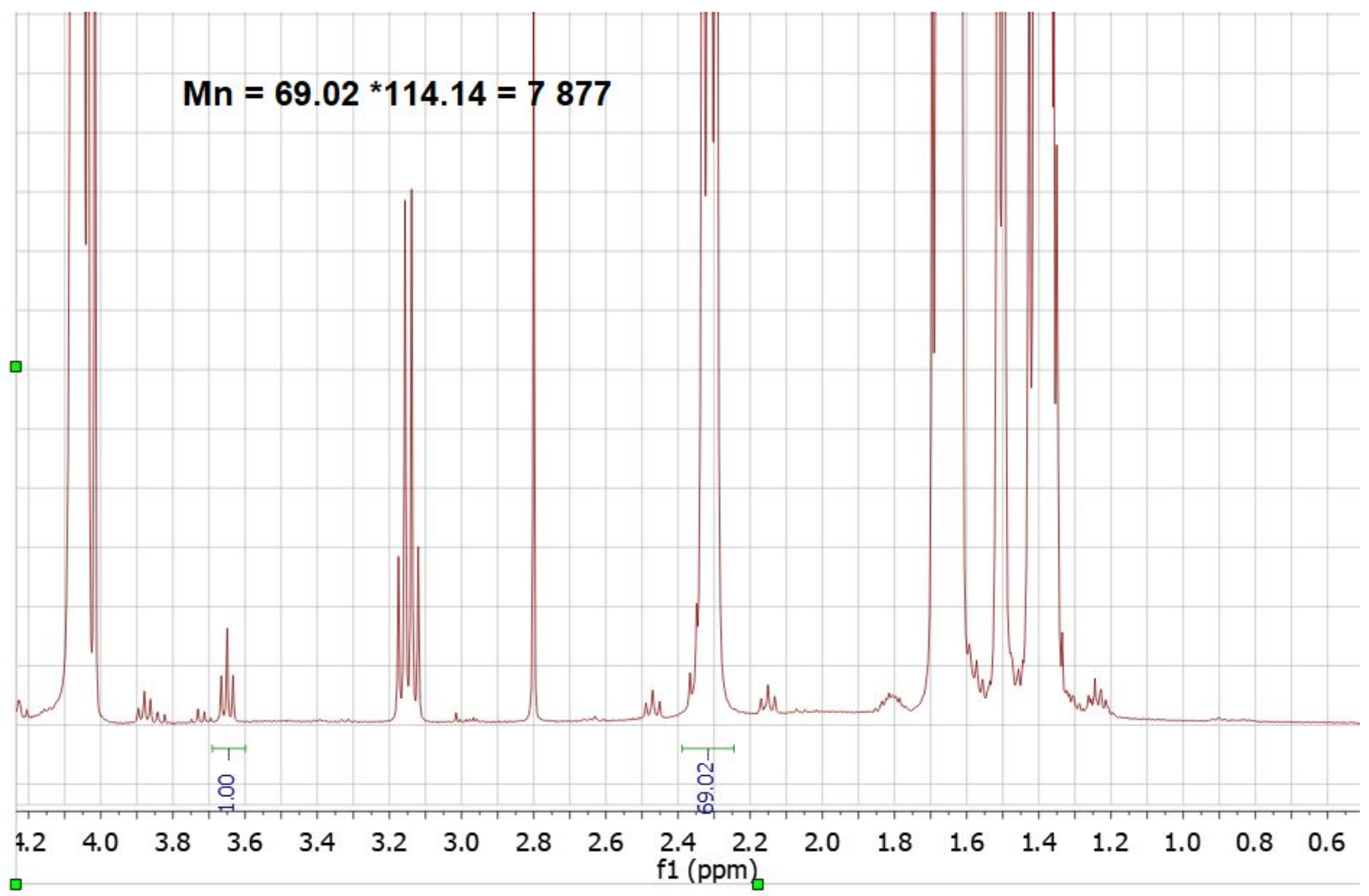

Figure S29. ${ }^{1} \mathrm{H}$ NMR for the free chains after SI-ROP in PC as a solvent

\section{Equation S1}

Equation used for calculation of the surface density.

(Weight Change in gram $) /\left(\left(D P^{*} M_{C L}{ }^{*} N^{*}\right.\right.$ Surface area)

The calculation was performed under the assumption that the surface area of the holo-cellulose fiber was $200 \mathrm{~m}^{2} / \mathrm{g}$ and that the weight loss during purification was the same for all fibers. 